\title{
Phospholipids and glycolipids mediate proton containment and circulation along the surface of energy-transducing membranes
}

\author{
Marcos Y. Yoshinaga ${ }^{1, *}, ¥, \dagger$, Matthias Y. Kellermann ${ }^{2, \dagger}$, David L. Valentine ${ }^{2}$, Raymond C. \\ Valentine ${ }^{3}$
}

1. University of Bremen, MARUM - Center for Marine and Environmental Sciences, Germany

2. University of California Santa Barbara, USA

3. University of California Davis, USA

* For correspondence Email: marcosyukio@gmail.com

¥ Current address: Institute of Chemistry of the University of São Paulo, Brazil

$\dagger$ These authors contributed equally to this work

(C) 2015. This manuscript version is made available under the Elsevier user license http://www.elsevier.com/open-access/userlicense/1.0/ 


\section{Abstract}

3 Proton bioenergetics provides the energy for growth and survival of most organisms in

4 the biosphere ranging from unicellular marine phytoplankton to humans. Chloroplasts harvest

5 light and generate a proton electrochemical gradient (proton motive force) that drives the 6 production of ATP needed for carbon dioxide fixation and plant growth. Mitochondria, bacteria 7 and archaea generate proton motive force to energize growth and other physiologies. Energy8 transducing membranes are at the heart of proton bioenergetics and are responsible for catalyzing

9 the conversion of energy held in high-energy electrons $\rightarrow$ electron transport chain $\rightarrow$ proton 10 motive force $\rightarrow$ ATP. Whereas the electron transport chain is understood in great detail there are 11 major gaps in understanding mechanisms of proton transfer or circulation during proton 12 bioenergetics. This paper is built on the proposition that phospho- and glyco-glycerolipids form 13 proton transport circuitry at the membrane's surface. By this proposition, an emergent membrane 14 property, termed the hyducton, confines active/unbound protons or hydronium ions to a region of 15 low volume close to the membrane surface. In turn, a von Grotthuß mechanism rapidly moves 16 proton substrate in accordance with nano-electrochemical poles on the membrane surface created 17 by powerful proton pumps such as ATP synthase.

19 Keywords: glycolipids; phospholipids; glycerolipids; energy-transducing membranes; proton 20 bioenergetics; von Grotthuß mechanism; long distance proton transport. 


\section{1. History}

The flow of protons through and on cellular membranes is central to bioenergetics, i.e.

26 supply of energy for life. Peter Mitchell, the father of the field of proton bioenergetics,

27 envisioned in 1961 [1] that the thermodynamic potential energy at equilibrium was coupled to a

28 proton gradient across or within energy transducing membranes (i.e. proton motive force, $p m f$ ).

29 While Mitchell's visionary "chemiosmotic" hypothesis is widely accepted today in its general

30 terms, at that time few structural details of proton pumps or ATP synthase were available; as a

31 consequence, Mitchell's revolutionary new hypothesis was severely debated (reviewed by [2]).

32 Mitchell's concept of delocalized bulk-to-bulk proton gradients was confronted with the idea of a

33 localized, i.e. limited distance of pmf coupled to ATP formation, membrane surface-to-surface

34 gradient [3-5]. The latter mechanism was demonstrated in biological systems, where

35 experiments systematically showed that protons do not immediately enter the bulk-water phase,

36 but are in fact retained on membrane surfaces [6,7]. These findings stimulated the first

37 publications suggesting membrane lipids as facilitators of lateral proton transfer [8,9].

38 Research activity on membrane-water interface proton transport intensified again in the

39 1990's. Two separate laboratories reported that protons ejected from cells of Halobacterium

40 salinarum by archaeal rhodopsin, acting as a proton pump, did not enter immediately the bulk

41 phase or medium [10,11]. Instead, protons effluxed by this light-energized proton pump hugged

42 the membrane surface while traveling a relatively long distance on their journey to ATP

43 synthases. These studies with purple membranes set the stage for several groups from different

44 research areas to establish the importance of membrane surfaces in proton circulation [12-24].

45 Please note that a complete review of references in the history of this field is beyond the scope of 
46 this paper. Furthermore, based on the thermodynamics of ATP synthesis, a membrane-water

47 interface mechanism is apparently required for proton circulation in energy transducing

48 thylakoid, bacterial and mitochondrial membranes [25,26]. Thus, it appears that the proton

49 gradients established at membrane surfaces are in fact essential for proton pumping activity of

50 integral membrane proteins of the respiratory chain complexes, e.g. ATP synthase [27-30].

51 While numerous lines of evidence confirmed a primary role of lipids in proton circulation

52 along membrane surfaces, a unified model that accounts for the great variety and specificity of

53 lipids in different types of membranes (Fig. 1; Table 1) is still missing. Given their negative

54 charge, anionic lipids have been hypothesized as trap and conduction vehicles (proton wells) for

55 proton transport [8], such that lipid-water interfaces would form a "network" for localized proton

56 sources (pumps) and sinks (ATP synthases) [9,38,39]. A "proton trap" function for oxidative

57 phosphorylation was also attributed to more specific lipids such as cardiolipin (CL) [40-42].

58 These models, however, do not fully integrate the distinct composition of lipids (e.g. the highly

59 variable proportions of phospho- vs. glycolipids; anionic vs. zwitterionic vs. neutral lipids; as

60 well as the absence of CL in thylakoid and most archaeal membranes) and their possible roles in

61 the bioenergetics of energy transducing membranes. Moreover, the idea of a few lipid classes

62 (e.g. CL) participating in the membrane's interface proton transport is consistent with the

63 localized proton gradients for ATP formation in respiratory supercomplexes [41-49]. The latter

64 concept implies that proton sources and sinks are located nearby, i.e. within a limited distance for

65 proton shuttling. However, this idea has been currently challenged by compelling data. These

66 recent studies have provided evidence for segregated respiratory complexes into microdomains

67 in E. coli [50,51], such that protons might have to travel long distances (thousands of $\AA$ ) between

68 efflux pumps and ATP synthase. 
This paper is built on the proposition that lipids are co-catalysts in the bioenergetics of

70 energy transducing membranes. Our challenge is to unify the roles of phospho- and/or glyco-

71 glycerolipids typical of archaeal, bacterial, thylakoid and mitochondrial membranes (Table 1)

72 into a general model for proton circulation hugging cell surfaces. We provide a critical

73 assessment of lipidomics in membranes from all three domains of life, discussing the proposed

74 model in face of current data on localized vs. delocalized respiratory complexes. This article

75 features the roles of lipids in bioenergetics, which might inform broader ecological

76 understanding such as life in extreme environments, primitive and extraterrestrial life, aging and

77 age-dependent diseases.

\section{Principles of proton circulation along membranes}

84 and sugar-based glycerolipids, are characteristic building blocks of all energy-transducing

85 membranes (Fig. 1; Table 1). In turn, energy-transducing membranes are broadly defined here as

86 any membrane involved with any aspect of proton bioenergetics or proton circulation. According

87 to this definition a synaptic vesicle is an energy transducing membrane, as are plasma and

88 excitatory membranes. Thus on total, most membrane surfaces in the biosphere are energy

89 transducing, with chloroplast and mitochondrial membranes being the most abundant. The total

90 surface area of these organelles (chloroplasts and mitochondria) is larger than the surface area of

91 all other membranes combined. Note that phospho- and glycolipids are also components of 
92 archaeal membranes even though ether-bound isoprenoidal chains as opposed to ester-bound

93 fatty acids remained a hallmark of archaea during the course of their evolution.

94 Glycolipids are signature lipids of photosynthetic membranes [36,52]. The importance of

95 glycolipids in ecology can be judged by the number of these building blocks produced annually,

96 an amount estimated to be greater than two billion metric tons. This value is derived from tracer

97 studies, which suggest more than ten percent of total fixed carbon ends up in chloroplasts with

98 roughly one fifth of this fraction as glycolipids [53,54]. Obviously, these are rough figures but

99 drive home the point that no other class of membrane lipids come close to this magnitude. Since

100 glycolipids are present in thylakoid membranes of plants, algae and cyanobacteria (Table 1) this

101 means that photosynthetic membranes enriched with glycolipids are the most abundant lipid

102 class among all other membrane surfaces involved in proton bioenergetics. While glycolipids are

103 considered as the most abundant, they tend to be found in specialized membranes such as

104 photosynthetic membranes, but are otherwise missing in many membranes such as the inner

105 membranes of E. coli and mitochondria. Conversely, phospholipids are universal and inseparable

106 from energy-transducing membranes. In spite of their importance, the molecular roles of

107 phospho- and glycolipids in proton circulation along membrane surfaces remain poorly

108 understood.

109 Data from comparative lipidomics and biochemical ecology tell us another interesting

110 rule of thumb about the universal role of the lipid's headgroup. E. coli has been a genetic

111 workhorse for mutant and recombinant analysis, and it is well known that a knockout or null

112 mutant of its bulk molecular species of lipids, i.e. phosphatidylethanolamine (PE), is lethal [55].

113 However, researchers found that by simply supplementing $\mathrm{MgCl}_{2}$ or engineering recombinants

114 that express foreign genes for glucose or galactose transferases, growth of a PE-minus mutant 
115 can be partially restored [56-59]. In the biosphere, especially in the ocean, a significant number

116 of organisms are faced with a chronic shortage of phosphate in their environment. Cyanobacteria

117 adapt to phosphate limitation by replacing their phospholipids with sulfoglycolipids [35],

118 whereas eukaryotic phytoplankton substitute aminolipids for phospholipids [60]. Not only

119 microorganisms substitute non-phospholipids for phospholipids under phosphate deprivation, but

120 also higher plants are capable of this lipid substitution ([61] and references therein). The caveat

121 of these data from the marine environment, plants and E. coli is that glycolipids and/or

122 aminolipids can substitute for phospholipids under certain conditions (see section 2.2). The

123 contrary has, however, not been observed.

124 The plant, Arabidopsis, is a model organism for genetic study and has proven to be

125 especially valuable in demonstrating the essentiality of glycolipids, specifically galactolipids

126 (reviewed by [61,62]). Mutants of Arabidopsis with deficiency in producing either mono or

127 digalactosyl lipids display severe effects in growth and functional capabilities of their

128 chloroplasts [63,64]. Moreover, it was demonstrated that glucolipids can substitute for

129 galactolipids, but even this exchange in sugar headgroup, i.e. glucose for galactose, affects

130 dramatically the maximal photosynthetic capacity of Arabidopsis [65]. Similarly, glucolipid

131 substitution for galactolipids in the cyanobacteria Synechocystis lead to a significant reduction in

132 photosynthetic activity and light energy utilization [66]. It is difficult to find a more thorough

133 and convincing set of data defining the essential nature of a single class of membrane lipids in

134 any organism. We suggest that phospholipids and glycolipids represent divergent solutions to the

135 fundamental need in cell bioenergetics: the requirement for maintaining proton conduction along

136 membrane surfaces. 

proton transport

This section is built on the concept that anionic lipids and bioenergetics are so tightly

142 linked that they are fundamentally inseparable. Indeed, as stated by Haines [8], there exists no

143 cellular membrane that lacks anionic lipids. The concept that negatively charged phospholipids

144 (Fig. 1), including CL, act as proton antennas and conduction vehicles for membrane-hugging 145 proton circulation is not a new idea [8,40]. It is well known that growth and activity of 146 recombinants of both Arabidopsis and E. coli deficient in anionic lipids are severely 147 compromised [67,68]. A closer look into the environmental data given in the section above 148 reveals that cyanobacterial cells adapt to phosphate limitation by replacing their phospholipids 149 with anionic sulfolipids [35]. Moreover, eukaryotic phytoplankton substitute zwitterionic betaine 150 lipids for zwitterionic phospholipids, but not the anionic phosphatidylglycerol (PG) [60]. Note 151 that in both cases the negatively charged headgroup is retained and phosphate is likely shunted to 152 more critical metabolites such as for DNA synthesis.

153 Once again this data highlights the fundamental importance of the negatively charged 154 headgroup rather than phosphate itself. Protons have a great affinity to "park" into this 155 negatively charged headgroup $[8,69,70]$. Recent data defining the role of lipids in giant 156 unilamellar vesicles as model to study the mitochondria inner membrane morphology [71-73] 157 help us illustrating these properties. Subjecting these purely lipidic vesicles, containing a mixture 158 of anionic cardiolipin and zwitterionic phospholipids typical of mitochondria (Table 1), to a local 159 external acidification caused membrane deformations that resemble the cristae of mitochondria 160 inner membranes. Further tests made with different headgroups of anionic phospholipids, 
161 including PG, phosphatidyl-inositol (PI) and -serine (PS), resulted in distinct morphological 162 changes [71-73]. More importantly, no changes in shape were noticed in vesicles containing 163 exclusively zwitterionic phospholipids [71]. This data using a membrane model indicates that the 164 electrostatic interaction between anionic phospholipids and protons results in deformation of 165 lipid vesicles attributable to local changes in $\mathrm{pH}$ at the membrane surface.

166 Despite the multiple functions of anionic lipids in cell membranes, we suggest that 167 anionic lipids are fundamental for proton circulation by simply placing protons on the membrane 168 surface normal. This leads to the question: what are the functions of other membrane-associated 169 zwitterionic phospholipids and sugar-based neutral lipids? It is well documented that 170 phospholipids are organized in membranes via electrostatic interactions and hydrogen bonding of 171 their headgroups, including the water molecules that are involved in the hydration shell of the 172 polar headgroups [69,74-78]. This continuing "network" of water molecules in charged 173 phospholipid headgroups (i.e. both anionic and zwitterionic lipids) would allow protons to move 174 laterally along the membranes surfaces by a von Grotthuß mechanism [79], instead of escaping 175 immediately to the bulk $[9,38,39]$. This latter mechanism is described in more detail in the next 176 sections. Recent data by Springer et al. [22] have shown that three different phospholipid 177 membranes, whose proton affinities vary by $7 \mathrm{pKa}$ units, enabled long-distance two-dimensional 178 proton migration along planar membranes $(70 \mu \mathrm{m})$. These authors concluded that protons are 179 retained and diffuse in the membrane's hydration layer as opposed to protons binding to fixed 180 buffers such as anionic lipids, as previously suggested [8,40,41].

181 Cell membranes composed mostly of anionic lipids are rare in nature, and haloarchaea 182 may represent the best-known exception. The cell membranes of these salt-loving archaea are 183 composed mostly of anionic phospholipids [80], and their growth and viability are dependent on 
184 relatively high concentrations of divalent cations (>75 $\left.\mathrm{mM} \mathrm{Mg}^{2+} ;[81]\right)$. Similarly, growth of a

185 lethal PE-minus E. coli, composed solely of anionic CL and PG, can be restored by

186 supplementing the media with divalent cations such as $\mathrm{Ca}^{2+}, \mathrm{Mg}^{2+}$ and $\mathrm{Sr}^{2+}[56,58,59]$. This

187 requirement for divalent cations in membranes composed mostly of anionic lipids suggests that

188 these ions may counteract the repulsive charges of negatively charged phospholipids in

189 haloarchaea and PE-minus E. coli, thereby avoiding proton leakage. Thus based on these

190 observations and the results from Springer et al. [22], it appears that a fundamental role of

191 zwitterionic lipids may be related to the electrostatic organization of cell surfaces, balancing the

192 net amount of negative charges, possibly for the purpose of proton transport along membrane

193 surfaces.

194 A breakthrough in understanding how protons might be contained within a latent (not 195 detectable by electron microscopy) layer on the membrane surface occurred in 2012. Wang and 196 colleagues [82] used nanochemical methodology to synthesize an $18 \AA$-thick, H-bonded lattice, 197 which they showed to act as a permeability barrier against protons (Fig. 2a). These authors 198 synthesized this nanomembrane to demonstrate how archaeal and bacterial cells might use such 199 H-bonded sugar lattices on their outer membrane surface as defenses against excessive acidity 200 damaging to the cell. In retrospect, we suggest that their nanomembrane sugar lattice model can 201 be directly applied to explain long-distance, membrane-water interface proton conductance on 202 photosynthetic membranes of chloroplasts and cyanobacteria (Fig. 2b). In fact, a careful 203 assessment of the lipidomics of $H$. salinarum, used as a biological model for long-distance 204 proton transport $[10,11]$, reveals that the outer leaflet of archaeal purple membranes are covered 205 by a triple sugar lattice of anionic sulfoglycolipids [85,86]. Similarly, neutral glycolipids are 206 major lipids of Sulfolobus [87], another archaeal membrane used to experimentally probe long- 
207 distance proton diffusion along membrane surfaces [12]. Collectively, these data illustrate that

208 anionic, zwitterionic and neutral lipids (Fig. 1) can be integrated into a single category: H-

209 bonded headgroup lattices for active proton or hydronium ion conduction or the "hyducton".

211 2.3. The "hyducton": introduction to the general model

This section introduces a hypothesis based on the concept that $\mathrm{H}$-bonded chains of water

214 molecules in lipid headgroups are the proton conduits for energy-transducing membranes (Fig.

2153 ). While the underlying concept is not new (see History section), our challenge is to integrate

216 the hyducton model and the role and essentiality of phospho- and/or glycolipids membranes in

217 the thermodynamic ecology of archaea, bacteria, plants and mitochondria. We first give a brief

218 explanation of how hydronium ions potentially move along the membrane surface via a von

219 Grotthuß mechanism. This concept has been used to explain proton transport across the 220 membrane, such as through gramicidin [88] and ion channels [89-91], with several reviews

221 available in the literature [92-96].

222 Negatively charged headgroups are known to interact with protons and other cations

223 including $\mathrm{Na}^{+}, \mathrm{K}^{+}, \mathrm{Mg}^{2+}$ and $\mathrm{Ca}^{2+}[97,98]$. Here, our attention is primarily on protons. According

224 to the general model, anionic headgroups with attached protons are found within the H-bonded

225 lattice of lipids along membranes. At this point, our model does not prove that lipids are proton

226 wells, but rather demonstrates that the proton-carrying anionic headgroups are clearly in a

227 position to participate in proton swapping via the von Grotthuß mechanism, with hydronium ions

228 or $\mathrm{H}_{3} \mathrm{O}^{+}$moving through this narrow channel (Fig. 3a). Protons leaving anionic headgroups and

229 binding water will form more $\mathrm{H}_{3} \mathrm{O}^{+}$that in turn influence the pool size of circulating protons in 
230 the conduit. However, when a proton hops from an anionic headgroup to a water molecule it

231 leaves behind a negative charge, which can be immediately filled by a $\mathrm{H}_{3} \mathrm{O}^{+}$breaking away from

232 another anionic lipid (Fig. 3b). Thus, proton swapping only slightly changes the net pool of $\mathrm{H}_{3} \mathrm{O}^{+}$

233 in the pipeline. However, this situation would change immediately should even a miniscule drop

234 in $\mathrm{H}_{3} \mathrm{O}^{+}$concentration occur for any reason. At this point, a net flow of protons from the

235 headgroups to water would occur and vice versa. According to this scenario anionic lipids might

236 be essential because they instantly give up their protons when needed and accept protons when

237 too many are present. Thus, the H-bonded lattice of lipid headgroups might behave as a classic

238 buffer against changes in $\mathrm{pH}$ and is fundamentally distinct from the proton well hypothesis

$239[8,40-42]$. The caveat is that this mechanism would be effective only if the protons in circulation

240 are carried in a small volume within a hyducton, preventing protons from leaving the

241 membrane's surface.

242 A considerable increase in proton mobility at $2 \AA$ radius compared with larger water-

243 channel pores has been shown by molecular dynamics simulation, providing evidence of

244 effective von Grotthuß water wire behavior when waters are in single file [99]. Other

245 mechanisms of proton transfer include transport by soluble buffers such as phosphates [100] and

246 the related phenomenon of water hydrolysis [101]. Although soluble buffers represent a labile

247 source of protons at generally much higher concentrations (mM; for water $\sim 55 \mathrm{M}$ ) than free

248 protons $(<\mu \mathrm{M})$, their diffusion rates are usually more than one order of magnitude lower than

249 that of protons in water [94]. Indeed, a wide range of diffusion coefficients has been reported for

250 proton transfer in lipid membranes, covering two orders of magnitude with the highest values

251 comparable to those in water $[10,11,18,22]$. We quote DeCoursey [92] to conclude on this

252 quandary: “... the speed of proton transfer may be less critical biologically than the 
253 establishment of conditions that allow it to take place in a controlled and predictable manner." In

254 other words, we suggest that proton pathways along the membrane surface are inherently

255 dependent on the blend of lipid structures, and that this emergent property has evolved under

256 selective pressure to fulfill the energetic requirements of the cell.

257 Another matter of debate in proton transport along membrane surfaces is the reasons why

258 protons stick to the surface and do not desorb to the bulk during long-distance transport. Recent

259 papers by Medvedev and Stuchebrukhov [23,102] provide a theoretical rationale as to the

260 implications of protons desorbing and re-adsorbing onto the membrane surface before

261 equilibrating into the bulk. This possibility introduced a challenge to the field of proton transport

262 along membrane surfaces. Wolf et al. [24] for example recognized: "We suspect the existing

263 conundrum on the existence of the bulk-mediated diffusion pathway originates from the fact that

264 the competing on-surface pathway is very sensitive to the membrane conditions". In the same

265 lines as the latter authors, we suggest that the surface-to-bulk proton exchange together with the

266 possibility of proton leakage through the lipid bilayer $[103,104]$ might be in fact the major

267 reasons explaining the predominance of certain classes of membrane lipids associated with

268 distinct environmental conditions (e.g. high/low pH and temperature; see section 5).

269 Long-distance proton transport by a hyducton in membrane surfaces offers a multitude of

270 benefits for bioenergetics. The ATP synthase is delicately regulated and requires precise

271 management of pmf and metabolic homeostasis. A detailed description of this important topic is

272 beyond the scope of this paper, but it is briefly considered here for completeness. The main point

273 is that ATP synthase responds to numerous signals including changes in $p m f$, adenyl phosphate

274 levels and acidity [105]. The low concentration of protons, literally a million times smaller than

275 that of other ions [96], circulating in the small volume of the hyducton suggests that slight 
276 changes in numbers of protons might be sensed by ATP synthase, in turn amplifying changes in

277 energy status and homeostasis. These changes are part of an elaborate regulatory feedback loop

278 modulating the activity of this powerful enzyme that is at the heart of proton circulation

$279[106,107]$.

280

281 2.4. Proton arithmetic

282

The concept that proton transport occurs in a specialized structure with a miniscule

284 volume raises many issues that we lump together as proton arithmetic. The underlying issue is

285 how many hydronium ions take part in proton bioenergetics, especially if they are localized on

286 the membrane surface. We do not yet offer a precise number but suggest some ways to gauge

287 this number. Calculating the number of free protons taking part in proton circulation in a

288 synaptic vesicle is a good place to start. How many protons does it take to charge a single

289 synaptic vesicle with $\mathrm{H}_{3} \mathrm{O}^{+}$needed to energize uptake of a standard load of glutamate, a

290 neurotransmitter? Since only one ATP synthase (V-type consuming ATP) molecule, on average,

291 is present per synaptic vesicle [108] the stage is set for the first lesson on proton arithmetic.

292 The number of protons in the cavity of a synaptic vesicle is estimated to be 0.1 per

293 vesicle [109] and our calculation based on $\mathrm{pH}$ [110] and volume [108] is 0.07 protons per

294 vesicle. For the cytoplasm of E. coli at pH 7 this number comes out to be 28 (Fig. 4), which is

295 supported by back of the envelope calculations for protons in a typical bacterial cell estimated at

29660 [112]. Proton arithmetic for chloroplasts is more complicated because of uncertainty about the

297 volumes assigned to the stroma and thylakoid lumen. We suggest that at this point an order of

298 magnitude is sufficient for these purposes. Interestingly, the numbers of protons are estimated at 
$299 \quad 0.6-3.6$ in thylakoid membranes with a lumen $\mathrm{pH}$ of 6 [113]. Note that these fractions of protons

300 are just a theoretical approximation based on $\mathrm{pH}$ and volume. However, they fundamentally

301 demonstrate that only a few free/unbound protons participate in the cell's bioenergetics,

302 consistent with the idea that proton availability is a key limiting factor controlling the rate of

303 proton transfer in biology (see review by [94]).

304 We have determined the size of a hyducton based on amount of polar lipids in a cell of $E$.

305 coli, water molecules per lipid headgroup and volume of a water molecule. The purpose of this

306 calculation, detailed in Fig. 4, is to understand the proton arithmetic inside the hyducton relative

307 to that of E. coli cytoplasm. The rationale is that a variation in $\mathrm{pH}$ of 1 unit from $\mathrm{pH} 7$ to 6 ,

308 important to ATP synthesis, would need only a few protons $(\sim 3)$ added into the hyducton

309 compared to more than 250 protons needed for the same $\Delta \mathrm{pH}$ in the cytoplasm (Fig. 4). In

310 support of our calculations, Cherepanov et al. [16] developed a model system and observed that a

311 change in proton concentration of up to $10^{-6} \mathrm{M}$ occurs at the membrane/bulk interface (or $\sim 3$

312 protons in the hyducton) when "pumps" ejected protons at the cell surface. We therefore suggest

313 that the few protons released by pumps may cause a significant $\Delta \mathrm{pH}$ shift in the hyducton, which

314 could then be used to generate the electrochemical gradient that drives production of ATP.

315 We now compare the proton arithmetic with data on the time scale of proton

316 bioenergetics. Ueno and colleagues have experimentally demonstrated in E. coli that the

317 maximum velocity of an ATP synthase is around 230 revolutions per second [114]. This

318 maximum velocity of an ATP synthase, with formation of $3 \mathrm{ATP} /$ revolution, is equivalent to 690

$319 \mathrm{ATP} / \mathrm{s}$. Based on the $\sim 1,000 \mathrm{ppm}$ of subunits atpE or atpC of E. coli ATP synthase (Protein

320 Abundance Database, http://pax-db.org) and estimated $3 \times 10^{6}$ proteins per $\mu \mathrm{m}^{3}$ (or the volume of

321 an E. coli [112]), the number of ATP synthases is in the range of 1,000 to 10,000 molecules/cell. 
322 These calculations reveal a turnover of 0.7 to 7 million ATP/s/cell. Another way to gauge this

323 number is experimental data showing that maximum yields of E. coli growing aerobically

324 correspond to 12 billion ATP/cell [115; see also http://bionumbers.org]. Considering a

325 generation time of $40 \mathrm{~min}$. (or $\sim 2,000 \mathrm{~s}$ ) for E. coli cells during aerobic growth [116], the

326 turnover can be estimate at 6 million ATP/s/cell. With a stoichiometry of 3-4 $\mathrm{H}^{+} / \mathrm{ATP}$ [117], the

327 numbers of protons circulating per cell for ATP synthesis is in the order of 20 million $\mathrm{H}^{+} / \mathrm{s}$.

328 Two major lessons can now be gleaned from proton arithmetic in E. coli: low availability

329 of protons for bioenergetics and massive number of protons supplied to ATP synthases per

330 second, a time scale in which protons at membrane surfaces theoretically equilibrate with the

331 bulk [118]. Thus while the hyducton may not be an absolute requirement, it potentially

332 represents an efficient pathway for proton transfer between sources and sinks along the

333 membrane surfaces. Comparatively, bulk-mediated desorption and diffusion will cause proton

334 loss into the bulk phase, even if membrane surface proton antennas (i.e. negatively charged lipids

335 or proteins) are involved [17,24].

336 As concluded by Cherepanov and colleagues [16], the membrane-water interface may

337 represent a potential $\mathrm{pH}$ barrier at cell surfaces allowing microbial life to exist in extremely

338 alkaline environments. In addition to alkaliphiles, we suggest that the hyducton is likely essential

339 to the bioenergetics of all life forms. From an ecological standpoint, however, it is important to

340 recall that the benefits of the hyducton might come with several risks that include, among others,

341 protons escaping from the membrane surface into the cytoplasm causing significant $\mathrm{pH}$ alteration

342 and protons crossing the lipid bilayer [103,104; see section 5].

343

344 2.5. Lipid headgroups enable long-distance proton transport through the hyducton 
If lipid headgroups buffer long-distance proton transport, what are their chemical features

347 that could account for this property? In a recent ab initio molecular dynamics study, phosphates

348 have been defined to possess the highest intrinsic proton conductivity of any known substance

349 [119]. According to the authors, due to its peculiar H-bonded topology and weak solvent

350 interaction, phosphoric acid is an exception among liquids with very strong H-bonds. The

351 formation of ordered structures by strong H-bonds tend to result otherwise in very slow proton

352 dynamics rather than high proton conductivity [119]. This important chemical specificity of

353 phosphates may confer high conductivity upon phospholipid-based, energy-transducing

354 membranes, enabling their function as a hyducton. It also reveals, however, that protons may

355 readily leave the membrane normal, i.e. escaping to the bulk or across the lipid bilayer, should a

356 slight change in the configuration of phospholipids occur at the cell's surface.

In order to evaluate the risks of proton leakage associated with phospholipids as

358 hyductons, we revisit data showing that PE-minus mutants of E. coli are partially rescued by

359 glycolipids and addition of divalent cations [56-59]. While glycolipids and divalent ions are not

360 exact substitutes for PE, they can certainly balance the negatively charge density of the PE-

361 minus membrane, thereby minimizing proton leakage from the hyducton. Compelling evidence

362 for proton leakage control by divalent cations is found in archaeal membranes of methanogens

363 composed mostly of anionic phospholipids. Methanosarcina species grown in low $\mathrm{Mg}^{2+}$

364 concentrations are observed exclusively as dense cell aggregates (cell packets). In contrast, cells

365 grown in high $\mathrm{Mg}^{2+}$ concentrations transition from aggregates to single cells displaying

366 comparatively higher growth yields [120,121]. These lessons from phospholipids are key for

367 understanding the roles of glycolipids in energy-transducing membranes. 
In section 2.1, we provided examples from photosynthetic membranes revealing that 369 phospholipids cannot substitute for glycolipids. This picture is reinforced by data from Salzberg

370 and Helmann [122] on B. subtilis. These authors reported a considerable slower doubling time of 371 mutants lacking glycolipids relative to others lacking single phospholipids. Surprisingly, this

372 study also revealed that compared to the wild type, viability and robust growth of single 373 phospholipid mutants of B. subtilis stand in sharp contrast with nonviable strains of PE- and CL374 minus mutants of E. coli [55]. While B. subtilis is devoid of an outer membrane, its presence in 375 E. coli was suggested to account, in part, for the difference in viability and growth of 376 recombinants [122]. However, no further explanation was provided as to the function of the outer 377 membrane in bioenergetics. By interpreting the data in B. subtilis from a hyducton perspective 378 we suggest: 1) glycolipids acting as proton shields enable robust growth rates of mutants lacking 379 each major phospholipid; 2) glycolipids are likely tethered to specific membrane domains (e.g. 380 near the entry/exit ports of major proton pumps) to minimize proton leakage. In other words, 381 glycolipids in B. subtilis may provide the hyducton with proton containment, a concept idealized 382 by Wang et al. [82] in their model for acidity resistance in archaea (Fig. 2). By analogy, we 383 suggest that the outer membrane of E. coli, forming the periplasmic space (zone between the 384 outer and inner membranes), represents the "roof above" for optimal function of the hyducton.

In the gut, E. coli faces a number of toxic molecules such as soap-like bile salts and 390 energy-uncoupling acids of their own making. In laboratory cultures, these acids accumulate as 
391 byproducts of sugar fermentation, in levels high enough to kill most of these cells. Nikaido [123]

392 has described the rationale and molecular architecture of the outer membrane of E. coli, with

393 lipopolysaccharides located exclusively in the outer leaflet, as a defense against these and other

394 toxic substances including antibiotics. Note that E. coli is often the cause of serious urinary tract

395 infections, a disease treated with antibiotics [124]. We consider an excess of protons to be a

396 potent toxin and suggest that the outer membrane shields the cell against this "problem"

397 according to mechanisms described by Nikaido [123]. Interestingly, a complex network of H-

398 bonds between neighboring sugar headgroups stabilizes the lipopolysaccharide leaflet, such that

399 this layer acts as a permeability barrier from the outside in and simultaneously from the inside

400 out. With the exception of porins openings to the cell's exterior, we reasoned that the robust

401 outer membrane architecture harnessed for blocking toxic compounds from entering the cell

402 [123] might also act to prevent the loss of metabolites such as protons effluxed into the

403 periplasmic space. In this scenario, protons in the periplasmic side of the inner membrane are

404 localized in a relatively small volume compared to the total cytoplasmic volume of the cell.

405 Thus, the outer membrane of E. coli has earmarks of a powerful permeability barrier for proton

406 containment.

407 The ecological function of the outer membrane as permeability barrier is also apparent in 408 the extreme flight of hummingbirds. These birds require virtually the entire volume of the 409 mitochondrial matrix to be filled with cristae, considerably enhancing the surface area for 410 allocation of plentiful ATP synthase and respiratory proton pumps (as shown in Fig. 5).

411 Presumably this adaptation reflects the need for mitochondria of breast muscle cells to energize

412 wing beats of greater than 100 per second ([125] see also [84]). Mitochondrial bioenergeticists

413 have known for decades about the restricted volumes of matrix and intermembrane space caused 
414 by cristae morphology, but the main point here concerns the mechanism of proton circulation in

415 this maze of cristae. According to the proton containment concept, the small volume of matrix

416 and intermembrane space sandwiched between opposing cristae provides an upper boundary to

417 each leaflet of the inner membrane. This tight arrangement in hummingbird mitochondria may be

418 used to trap or localize protons that escape the phospholipid-based hyducton (Fig. 5). This proton

419 containment strategy essentially enhances the efficiency of proton circulation to meet the 420 extreme energy required by the flight of hummingbirds.

421 For the purpose of clarification, an outer membrane as proton containment of 422 phospholipid-dominated membranes is not bioenergetically more effective than the glycolipid 423 one. In fact, growth rates of the glycolipid-containing B. subtilis are comparable to those of $E$. 424 coli [126]. Thus similar growth rates of mutants lacking phospholipids compared to the wild type 425 in B. subtilis [122] may reveal glycolipids as a conservative strategy for harnessing energy. That 426 is, conserving significant levels of protonic energy (i.e. by avoiding proton leakage) is equivalent 427 to making more energy. Not surprisingly, sugar-based headgroups are widespread among 428 archaea $[127,128]$, which are especially well adapted for energy conservation in environments 429 under chronic energy stress [129]. Glycolipids are also signature lipids of light-harvesting 430 membranes, and this topic will be covered in detail in section 3.3. In summary, we suggest that 431 the primary biochemical basis for glycolipid-containing membranes is both energy conservation 432 and energy efficiency. Conversely, cell membranes lacking glycolipids such as E. coli and 433 mitochondria need to balance the energy costs associated with the proton containment strategy 434 (i.e. outer membrane) and the benefits of high proton conductance within the hyducton made of 435 phospholipids. Lessons from ecology indicate control of environmental conditions on membrane 
436 lipid composition, which in turn modulates the hyducton composition to meet the energy

437 demands for life.

439 2.7. Grotthuß-type proton transfer in the hyducton and integral membrane proteins: effects of 440 point mutations

443 at the cellular membrane level. The key to proton transfer by a von Grotthuß mechanism is the 444 hopping of protons in a well-aligned H-bonded network ([92]; Fig. 3). Water wires organized via 445 H-bonded amino acid side chains inside powerful proton pumps have been revealed by high446 resolution X-ray crystallography (e.g. bacteriorhodopsin, cytochrome oxidases; see $447[94,130,131])$. This H-bonded network is recognized as the main pathway of proton transfer 448 across membranes, and thus its efficiency depends on close proximity of amino acids to the point 449 of hydrogen bonding (e.g. reviewed by [94,96]). Indeed the essentiality of mobile water as 450 gateways for proton transfer has been defined by point mutation of amino acid side chains within 451 integral membrane proteins. Wraight [94] concluded that although key residues may result in 452 irreplaceability, peripheral mutations do not alter the general functionality of the proton transfer 453 pathway. These observations on efficiency of proton transfer by water wires in membrane 454 proteins suggest a remarkable similarity to the organization of water molecules in lipid surfaces $455[77,78,98]$, and perhaps the functional capabilities of the hyducton as discussed below.

456 It is generally accepted that genetic manipulation of lipid metabolism in bacteria and 457 yeast provides mutant strains lacking a range of membrane lipid classes with largely unaffected 458 viability [55,66,122,132-134]. For instance, growth of CL-minus mutants of the yeast 
459 Saccharomyces cerevisiae in glucose is largely unaffected relative to the wild type at $30^{\circ} \mathrm{C}$, but

460 displays severe defects in mitochondrial function and an apparent decrease in membrane

461 potential $[135,136]$. Similarly to yeasts, Arabidopsis and Synechocystis mutants with substitution

462 of a single sugar in essential digalactose headgroups could restore overall growth, but not the

463 total photosynthetic capacity of these organisms $[65,66]$. The above-mentioned studies

464 collectively suggest that a well-balanced lipid headgroup composition is likely required for

465 optimal functioning of the hyducton (Fig. 3). This observation appears in contrast with the

466 robustness to mutation of amino acids side chains for proton transfer in integral membrane

467 proteins [94]. We attribute this difference to the fact that proton shuttling through the H-bonded

468 network of lipid headgroups may occur at distances several orders of magnitude longer than that

469 of amino acid water channels, e.g. $70 \mu \mathrm{m}$ or $700,000 \AA$ in planar membranes [22] vs. $18 \AA$ in

470 gramicidin [137]. We thus propose that the hyducton is an emergent feature, evolutionarily

471 honed to provide an arrangement of H-bonded structures via lipid headgroups, which depends

472 not just on the charged and non-charged nature of glyco- and phospholipids, but also on the

473 characteristics of their lipid tails $[83,84,138]$.

474

475 3. Case histories of hyductons chosen from all three domains of life

476

477 This section showcases the proposed bioenergetic relevance of the hyducton (Fig. 3) in

478 four exemplary membranes that span the spectrum of life's domains. We start with the purple

479 membrane of haloarchaea, on which early studies of long-distance proton transport were

480 performed. We then discuss the hyducton in two idealized models for $E$. coli, highlight the

481 importance of lipid composition for the hyducton in photosynthetic organisms including 
482 chloroplasts of eukaryotes and cyanobacteria, and end by considering the hyducton in

483 mitochondrial membranes.

484

485 3.1. Lipidomics of the purple membrane in haloarchaea

$H$. salinarum has been used as a model system for membrane-water interface proton transport $[6,10,11]$. In this haloarchaeon, the purple membrane (PM) converts light into chemical 489 energy [139], i.e. proton pump, and oxygen is not evolved during this process. The PM is an 490 island within the membrane of $H$. salinarum with an extremely high protein-to-lipid ratio 491 ( 75:25), featuring a membrane-spanning bacteriorhodopsin as the only protein of this domain 492 [140]. Note that the PM may cover up to fifty percent of the total membrane surface of the cell 493 [141], and protons must travel from the PM, which is devoid of ATP synthase, to ATP synthases 494 localized in respiratory lipid domains as far away as 5,000 $\AA$.

The membrane surfaces of $H$. salinarum are composed of both phospho- and glycosidic 496 isoprenoidal diethers [142]. Interestingly, the distribution of these lipids on the leaflets of PM is 497 asymmetrical $[85,86]$. As shown in Fig. 6a, whereas phospholipids (in green) are mostly present 498 in the inner leaflet, the sulfated triglycosyl lipids (in yellow) are located at the outer leaflet of the 499 PM. This asymmetrical localization of glycolipids to the exterior of the PM has been attributed to 500 the vectorial nature of the proton pumping activity $[85,130]$. Here, we reinforce this idea 501 suggesting that the triple-sugar headgroup provides essential containment for protons being 502 transported in $H$. salinarum. That is, the H-bonded triglycosyl headgroups together with their 503 anionic character, secured by negatively charged sulfated moieties at the top of these structures, 504 are proposed to efficiently hold protons close to the membrane's surface. This conservative 
505 proton containment strategy not only meets the permeability barrier properties of the hyducton,

506 but also focuses protons for long-distance transfer. Gradients created by powerful and opposing

507 proton pumps, i.e. ATP synthase and bacteriorhodopsin, determine the directionality of proton 508 transport (Fig. 6a).

509 Given the specific association of sulfated triglycolipids with bacteriorhodopsins, these

510 lipids are also predicted to be essential for the formation of purple membranes in haloarchaea

$511[86,130,143]$. Sulfated glycolipids can represent a significant proportion of total membrane

512 lipids, up to $30 \%$ [142], especially in genetically modified strains of $H$. salinarum with high-

513 bacteriorhodopsin content (e.g. L33 used by [144]). In contrast to previous studies, our recent

514 lipidomics survey revealed the absence of these glycolipids in a $H$. salinarum wild type [32].

515 Collectively, these observations indicate that amounts of sulfated triglycolipids may be likely

516 proportional to content and/or activity of purple membrane in H. salinarum. Indeed, based on ion

517 binding motifs of their ATP synthases, haloarchaea in general are known to primarily use $\mathrm{Na}^{+}$as

518 coupling ion for bioenergetics [145], such that $H$. salinarum may abandon use of the purple

519 membrane for ATP formation under certain conditions.

521 3.2. Electrochemical poles generated by microdomains of respiratory complexes in bacteria

523 Fluorescent imaging has been used to elucidate subcellular localization, mobility and 524 stoichiometry of respiratory complexes in the inner membrane of bacteria such as E. coli [47] 525 and B. subtilis [146] and thylakoid membranes of cyanobacteria [49]. These studies have 526 collectively suggested co-localization of clusters of these complexes on the nanometer scale, e.g. 527 ATP synthase and succinate dehydrogenase in B. subtilis [146]. These patches of bioenergetics 
528 domains are mobile and resemble those of respiratory supercomplexes in mitochondria and

529 plants [43-45,147]. Moreover, data by Liu et al. [49] provided additional evidence for dispersal

530 of the respiratory complexes of cyanobacteria after induction by moderate light intensity. Liu et

531 al. [49] further suggested that this redistribution of respiratory complexes matched the

532 distribution of photosynthetic complexes, leading to electron exchange between both respiratory

533 and photosynthetic electron transport chains. Note that in both cases, the generated proton

534 gradient would benefit from transport by the hyducton linked to ATP synthase. The co-

535 localization of ATP synthase within respiratory complexes also suggests relatively short-distance

536 proton transfer in bacteria (Fig. $6 b_{1}$ ) as compared to the purple membrane hyducton examined

537 above. However, most recent data from this field suggest that the concept of proton circulation in

538 bacteria is entering a new era involving microdomains of respiratory complexes.

539 Perhaps the most exciting data involves mobile specialized bioenergetics domains, 100-

$540200 \mathrm{~nm}$ in diameter, consisting of tens to hundreds of molecules of respiratory complexes, as

541 exemplified in E. coli [50,51] (Fig. 6 $\mathrm{b}_{2}$ ). In these studies the labeled microdomains were NADH

542 dehydrogenase (Complex I), cytochrome bd-I oxidase, cytochrome $\mathrm{bo}_{3}$ oxidase, $\mathrm{F}_{0} \mathrm{~F}_{1}$ ATPase,

543 and succinate:fumarate oxidoreductase (Complex II). The surprising aspects of these data include

544 the formation of bioenergetic microdomains composed of only one component of the electron

545 transport chain, the relatively large numbers of enzyme complexes present (10 to 180 molecules)

546 and the lateral movement of individual domains across the membrane surface. It was also

547 suggested that ubiquinone shuttles electrons long-distances between redox complexes localized

548 in membrane patches. Data from Llorente-Garcia and colleagues [51] suggests that there is both

549 long-range electron transfer and delocalized pmf involved in the bioenergetics of E. coli. We 
suggest that $E$. coli might have evolved a hyducton system for long-distance proton transport,

551 linking delocalized sources to sinks for efficient energy production (Fig. $6 \mathrm{~b}_{2}$ ).

552 We further speculate that the network of respiratory complexes segregated into patches of 553 several molecules, rather than a few co-localized supercomplexes (Fig. 6 $b_{1}$ ), might create 554 powerful electrochemical poles for proton bioenergetics. For example, 48 ATP synthase 555 molecules working in close proximity [51] mean that the electrochemical poles in the vicinity of 556 this bioenergetic microdomain would be expected to be stronger compared to a single molecule 557 functioning alone (Fig. 6b). Thus to be energetically advantageous, it appears that the spatially 558 segregated electrochemical poles may benefit from hyductons enabling long-distance proton 559 transport in E. coli. The existence of these poles has potential revolutionary consequences in 560 understanding proton transfer in general, including the distribution of ATP synthases in both 561 thylakoid and mitochondrial membranes [148]. modified by simply coating both leaflets of photosynthetic membranes with a digalactose, $\mathrm{H}-$

567 bonded sugar lattice covering the lumenal region versus a monogalactose coating for the stromal membrane leaflet of the photosynthetic bilayer (Fig. 6c). Pioneering data on sidedness of

569 thylakoid membranes of higher plants were published several decades ago $[151,152]$. These data

570 show that transmembrane distribution patterns of monogalactosyldiacylglycerol (MDGD) and

571 digalactosyldiacylglerol (DGDG) lipids are universal among a variety of plants. However, the

572 biochemical rationale to explain the remarkable asymmetry of thylakoid membranes in which 
573 MDGD is highly enriched in the outer leaflet in contrast to DGDG enriched in the inner leaflet

$574[52,152]$ remains a mystery. The importance of this question is highlighted by recognition that

575 photosynthetic membranes displaying galactolipid asymmetry are the most abundant and

576 essential membranes in the biosphere [53,54].

577 Although the asymmetry quandary remains unanswered, the hyducton model for

578 chloroplasts as described below might help to explain biochemical functions related to the

579 polymorphic membrane structure contributed by galactolipids (e.g. MGDG forms hexagonal II

580 phase). Once again we borrow from the model of Wang and colleagues [82] who explained the

581 membrane asymmetry of an extreme acidophilic archaea on the basis of a permeability barrier

582 against toxic levels of acidity in the medium. Note that the asymmetry question of archaea

583 centers on $\mathrm{pH}$ as low as $\mathrm{pH}$ 1-2 outside of the cell. Clearly, membrane components are denatured

584 at such low $\mathrm{pH}$, especially on the membrane surface. Thus, according to these authors, only the

585 most vulnerable membrane surface (outer leaflet) is protected through $\mathrm{pH}$ homeostatic

586 mechanisms guarding the cytoplasm against drastic shifts in $\mathrm{pH}$. This concept led us to ponder

587 that a digalactose shield against acidity might be more robust than a monogalactose, H-bonded

588 lattice (Fig. 6c). This is consistent with the well-known quandary of lumenal pH of chloroplasts,

589 which can become surprisingly acidic, well below $\mathrm{pH}$ 6, especially under conditions of high

590 illumination [153]. Thus, placing the digalactose lattice on the lumenal leaflet [52,152] makes

591 sense from the standpoint of a permeability shield against toxic levels of acidity. It has been

592 proposed that the photosynthetic machinery begins to be denatured as $\mathrm{pH}$ drops as low as $\mathrm{pH} 4.5$

593 in chloroplasts $[113,150]$. Why Mother Nature evolved a photosynthetic apparatus running so

594 close to a toxic threshold of $\mathrm{pH}$ remains an open question. 
In summarizing this section, we point to two essential functions for the galactose sugar

596 lattices of photosynthetic membranes. The first involves acidity protection of photosynthetic

597 machinery on the lumenal membrane surface. The second involves containment or localization

598 of protons near the membrane surface as a prerequisite for efficient, long-range proton

599 circulation. Surprisingly, the mechanisms for acidity tolerance and efficiency of proton

600 circulation are proposed to be the same - an interface that facilitates lateral proton transport, but

601 that simultaneously acts as a permeability barrier selective against both entry and exit of protons.

\subsection{Mitochondrial cristae as hyducton}

Fig. 6d depicts a model for the hyducton in mitochondrial inner membranes. The main

606 point of this model concerns the spatial segregation of proton sources (complexes I, III and IV of

607 the electron transport chain) and sinks (ATP synthases), respectively at the flat and curved 608 regions of the cristae membrane $[154,155]$. The localization of ATP synthase dimers, organized 609 as ribbons at the curved regions of the inner membrane cristae is a common feature of 610 mitochondrial membranes in mammals, fungi and plants, but not in chloroplasts, archaea and 611 bacteria $[148,155]$. The hyducton may provide three major bioenergetic advantages for 612 mitochondria. Firstly, protons generated by powerful pumps and moving along the hyducton on 613 either side of the cristae will securely reach the ATP synthases organized as dimers at the cristae 614 tips, minimizing loss of protons during delivery. Secondly, co-localization of rows featuring 615 several ATP synthase dimers at the curved ridges of cristae [156] may create electrochemical 616 poles for an optimum proton gradient, as in distributed microdomains of E. coli inner membrane 617 (Fig. 6b 2 ). And finally, recent data by Klotzch et al. [30] provided evidence for a preferential 
618 localization of the uncoupling protein 4 (UCP4) to the outside of cristae membranes, in the inner

619 boundary membrane. These authors suggested that UCP4 does not compete for protons with

620 major proton pumps, but may dissipate excessive proton gradients. The rationale is that when too

621 many protons are available at the cristae hyducton, uncoupling proteins may release excess

622 protons in a spatially segregated region of the mitochondrial inner membrane as a release valve.

\section{5. Benefit/risk analysis of the hyducton}

625 In developing the hyducton model described here, one of the first questions we asked 626 was: how robust are hyductons, from an ecological standpoint? Recall that Wang and colleagues

627 [82] were motivated to develop their model not as a conduit for proton transport but rather as a 628 defensive shield protecting acidophilic archaea against toxic levels of acidity. The point is that 629 the hyducton model was born in the world of extremophiles, more specifically a 630 thermoacidophilic archaeon Thermoplasma acidophilum (Table A1). The acidity model above 631 involves $\mathrm{pH}$ as low as $\mathrm{pH}$ 1-2 (Fig. 2a), which suggests that lowering seven units of $\mathrm{pH}$ does not 632 breach the H-bonds in glycolipids. However, it is interesting to attempt to identify conditions or 633 agents that rupture $\mathrm{H}$-bonds of $\mathrm{H}$-bonded glycolipid lattices resulting in uncoupling proton 634 bioenergetics catalyzed by this structure.

635 Table A1 summarizes a selected list of extremophilic membranes and highlights the 636 apparent limits of conditions for which glycolipids can function as hyducton lattices. The 637 rationale for this data analysis lies in the assumption that H-bonded sugar lattices are involved in 638 proton circulation and that breaching the H-bonded network would render the lattice useless. 639 However, since H-bonds can instantly reform after breaking [194], agents or conditions that 640 depolymerize the sugar lattice must be persistent. As shown in Table A1, glycolipids appear to 
641 be not only widely distributed, but are also functionally robust insomuch as they resist a range of

642 moderate to strong stresses or environmental insults. For example, glycolipids of thermophilic

643 cyanobacteria function at temperatures of 42 to $74^{\circ} \mathrm{C}$ in hot springs from Yellowstone National

644 Park [195], whereas glycolipid-enriched membranes of hyperthermophilic methanogens function

645 at least up to $100^{\circ} \mathrm{C}$ (e.g. Methanopyrus kandleri; [196]). The putative sugar lattice of the purple

646 membrane of haloarchaea functions at near saturating concentrations of salinity (about $5 \mathrm{M} \mathrm{NaCl}$;

647 [197]). Archaea often can be classified as energy extremophiles [129] and most of them

648 synthesize glycolipid-based membranes [127,128]. The chloroplast of Antarctic eukaryotic

649 phytoplankton is an example of an extremophilic organelle harvesting light near $0^{\circ} \mathrm{C}$ [84].

650 We next deal with poisons or inhibitors that might disrupt the permeability properties of a 651 sugar lattice and thus, uncouple bioenergetics. Agents, chemicals and conditions that break H-

652 bonds holding biopolymers together are well known. For example, both $\mathrm{NaOH}$ and $\mathrm{LiCl}_{2}$ 653 treatments disrupt H-bonds of chitin (glucosamine) polymers, which along with cellulose are the 654 most abundant polysaccharides in the biosphere [198,199]. In fact, data in the chemical literature 655 shows that hydroxyl ions $\left(\mathrm{OH}^{-}\right)$are very good receptors of H-bonds [199,200] and this property 656 alone is a red flag suggesting $\mathrm{OH}^{-}$might readily disrupt $\mathrm{H}$-bonds of hyductons. However, given 657 that broken $\mathrm{H}$-bonds can immediately reform and $\mathrm{OH}^{-}$-mediated $\mathrm{H}$-bonds are fleeting, there is 658 room for doubt that the strong donor function alone explains the H-bond-breaking behavior. 659 Recently, the hydrogen $(\mathrm{H})$ of $\mathrm{OH}^{-}$has been shown to $\mathrm{H}-$ bond with water [201]. The point is that 660 this dual nature of $\mathrm{OH}^{-}$chemistry might allow this ion to not only readily attack the $\mathrm{H}$-bonds of a 661 sugar lattice, but also to pry open the bonds long enough to form molecular holes for protons to 662 escape and $\mathrm{OH}^{-}$to leak in. As shown in Table A1, it appears that glycolipids, which are 663 otherwise widely distributed in high temperature and low $\mathrm{pH}$ conditions, are not prevalent in 
664 obligate alkaliphilic haloarchaea [80,153] and Bacillus [34]. This is negative data, but it is 665 consistent with $\mathrm{OH}^{-}$acting specifically as a poison against $\mathrm{H}$-bonded, sugar lattices.

666 Krulwich and colleagues [202] have reviewed the bioenergetics of alkaliphiles and it is 667 clear that remarkable adaptations are required to live in an alkaline world. These include cell 668 envelopes as permeability shields for membrane surfaces, such as the outer membrane in bacteria 669 [123], peptidoglycan layers in archaea [203] and cell walls in cyanobacteria [204]. While 670 alkaliphilic cyanobacteria ( $\mathrm{pH}$ 9) are known [205] and seem to defy the $\mathrm{OH}^{-}$rule, galactolipid671 enriched membranes of these cyanobacteria may be located well away from direct contact with 672 bulk $\mathrm{OH}^{-}$in the environment, protected by their robust cell walls [204]. It seems clear from an 673 ecological perspective that $\mathrm{OH}^{-}$(alkalinity) in contrast to acidity disrupts glycolipid-based 674 hyductons in direct contact with $\mathrm{OH}^{-}$. Apparently, building a H-bonded sugar lattice to support 675 bioenergetics is not a common adaptation among alkaliphiles. Thus the hyducton model helps 676 explain why obligate alkaliphilic haloarchaea and Bacillus lack glycolipids. The final topic in this section involves the hyducton as being a unit of the light-harvesting 678 membrane surface of chloroplasts and cyanobacteria, which support the most essential process in 679 global ecology - photosynthesis (Fig. 6c). According to the sugar lattice hypothesis (Fig. 2), the 680 H-bonds among polyhydroxy glycosidic headgroups create a lipid domain fixed in space. In 681 essence, H-bonds are envisioned to polymerize the vast area of photosynthetic and other 682 glycolipid membrane surfaces into a specialized, domain-like lipid structure where headgroups 683 have limited lateral or rotational mobility. Excessive escape of protons to the bulk phase defeats 684 the purpose of a hyducton in photosynthesis and protons leaking into the cytoplasm might be 685 catastrophic, resulting in uncoupled bioenergetics. 
Linus Pauling popularized H-bonds for organic chemists [206] while Watson and Crick

687 did the same for biologists. Hydrogen bonds possess some ideal properties for proton 688 bioenergetics and in previous sections we highlighted that photosynthesis, among other 689 processes, depends on such bonding. Depending on their local environment, especially the 690 presence or absence of water, H-bonds can be ca. 15 times stronger in membranes than van der

691 Waals forces [207]. The fact that H-bonds display an entire spectrum of sub-covalent bond 692 energies provides great versatility defining the properties of critical biological membranes.

693 Recall that H-bonds are essential for specialized membrane lipids ranging from myelinated axons

694 to photosynthetic membranes, the latter representing the major membrane lipid surface in the 695 biosphere.

\section{Conclusions}

The hyducton hypothesis provides a testable model for proton transport and utilization, 699 but many uncertainties remain. We suggest that the hyducton is vital to proton bioenergetics and 700 proton circulation on a global scale. Some of the most convincing data supporting the 701 fundamental roles of the hyducton in ecology come from genetic analysis of galactolipid 702 knockout mutants of plants. We interpret this data as evidence that the biosphere's primary 703 productivity is dependent not only on galactolipids, but also on the emergent property of proton 704 conductivity enabled by these membrane lipids. In the absence of membrane glycolipids, the 705 numerous great cycles of nature including the $\mathrm{C}, \mathrm{O}$ and $\mathrm{N}$ cycles would not function as they do 706 today. Outside the photosynthetic world, many archaeal membranes important to these cycles, 707 such as the ones from methanogens and ammonia oxidizing archaea, are enriched in glycolipids 708 (Tables 1 and A1). However, in spite of the massive production of glycolipids in the biosphere, 
709 phospholipids (particularly the ones carrying a negative charge) are more ubiquitous and

710 essential in all life forms. In one sense the concept of negatively charged phospholipid

711 headgroup acting directly as a biocatalyst for proton bioenergetics comes from the hypotheses

712 that anionic phospholipids act as proton antennas for parking protons in circulation $[8,40]$. We

713 suggest that anionic lipids behave not only as proton antennas, but also act as circuits for proton

714 delivery (Figs. 3 and 6). This is an exciting area for future research.

715 According to the hyducton hypothesis, the directionality of proton flow is expected to

716 allow protons to travel distances of tens of thousands $\AA$ (e.g. cristae of hummingbird

717 mitochondria, Fig. 5). Recent data from E. coli suggest that a limited number of electrical poles

718 occur on the surface of the cytoplasmic membrane [50,51]. These poles, both positive and

719 negative, are formed on the membrane surfaces when key proton pumps such as ATP synthase

720 aggregate together and thus work in unison as a specialized bioenergetic microdomain for

721 pumping protons. This brings a Mitchell's delocalized electrochemical gradient and a von

722 Grotthuß mechanism of proton movement into the picture in E. coli. Two centuries ago von

723 Grotthuß showed that protons in water move from all directions to a negative pole, and this rule

724 may apply to proton transfer along the inner membrane of E. coli. It is interesting to note that a

725 von Grotthuß mechanism may also play an essential role in proton transfer within ATP synthase

726 and other proton pumps important in proton bioenergetics [105,131]. Thus, it is not a complete

727 surprise that once protons exit a proton pump to the membrane surface, a von Grotthuß

728 mechanism mediated by anionic lipid headgroups might transfer this ion via hyducton to its entry

729 portals on another species of proton pump.

730 The concept of the hyducton as presented in this work remains a hypothesis. If the

731 hyducton hypothesis withstands testing, it carries grand implications for evolution of emergent 
732 properties at the cellular scale (e.g. likely to act as a selective pressure on membrane lipid

733 composition) as well as for physiology associated with global warming, human diseases and

734 aging. 


\section{Acknowledgements}

Special thanks go to Cindy Anders whose help was critical in many ways during preparation of the manuscript. We are also in debt to Lars Wörmer for insightful comments on this article and Ron Milo for helpful discussions. We thank the editor and an anonymous reviewer for the thoughtful comments that significantly improved this work. A number of experiments reported here involving the ecological role of lipids was carried out in the laboratory of Prof. Kai-Uwe Hinrichs. DLV and MYK received funding from United States National Science Foundation (OCE-1046144 and OCE-0950600). This is contribution \#1 from the Membrane Lipid Code Cracking Society (http://mlccs.jimdo.com).

\section{References}

1. Mitchell P. Coupling of photophosphorylation to electron and hydrogen transfer by a chemiosmotic type of mechanism. Nature 1961;191:144-8.

2. Junge W. Bioenergetics in mitochondria, bacteria and chloroplasts. Biochem Soc Trans 2013; 41:1207-18.

3. Williams RJP. The multifarious couplings of energy transduction. Biochim Biophys Acta 1978;505:1-44.

4. Kell DB. On the functional proton current pathway of electron transport phosphorylation, an electrodynamic view. Biochim Biophys Acta 1979;549:55-99.

5. Williams RJP. The structures of organelles and reticula: localized bioenergetics and metabolism. Chembiochem 2001;2:637-41.

6. Michel H, Oesterhelt D. Electrochemical proton gradient across the cell membrane of Halobacterium halobium: comparison of the light- induced increase with the increase of intracellular adenosine triphosphate under steady-state illumination. Biochemistry 1980;19:4615-9.

7. Arata H, Takenaka I, Nishimura M. Flash-induced proton release in Rhodopseudomonas sphaeroides spaeroplasts. J Biochem 1987;101:261-5. 
8. Haines TH. Anionic lipid headgroups as a proton-conducting pathway along the surface of membranes: a hypothesis. Proc Natl Acad Sci USA 1983;80:160-4.

9. Prats M, Teissié J, Tocanne J-F. Lateral proton conduction at lipid-water interfaces and its implication for the chemiosmotic-coupling hypothesis. Nature 1986;322:756-8.

10. Heberle J, Riesle J, Thiedemann G, Oesterhelt D, Dencher NA. Proton migration along the membrane surface and retarded surface to bulk transfer. Nature 1994;370:379-82.

11. Alexiev U, Mollaaghababa R, Scherrer P, Khorana HG, Heyn MP. Rapid long-range proton diffusion along the surface of the purple membrane and delayed proton transfer into the bulk, Proc Natl Acad Sci USA 1995;92:372-6.

12. Vilalta I, Gliozzi A, Prats M. Interfacial air/water proton conduction from long distances by Sulfolobus solfataricus archaeal bolaform lipids. Eur J Biochem 1996;240:181-5.

13. Gabriel B., Teissié J. Proton long-range migration along protein monolayers and its consequences on membrane coupling. Proc Natl Acad Sci USA 1996;93:14521-5.

14. Antonenko YN, Pohl P. Coupling of proton source and sink via $\mathrm{H}^{+}$-migration along the membrane surface as revealed by double patch-clamp experiments. FEBS Lett 1998;429:197200.

15. Smondyrev AM, Voth GA. Molecular dynamics simulation of proton transport near the surface of a phospholipid membrane. Biophys J 2002;82:1460-8.

16. Cherepanov DA, Feniouk BA, Junge W, Mulkidjanian AY. Low dielectric permittivity of water at the membrane interface: effect on the energy coupling mechanism in biological membranes. Biophys J 2003;85:1307-16.

17. Serowy S, Saparov SM, Antonenko YN, Kozlovsky W, Hagen V, Pohl P. Structural proton diffusion along lipid bilayers. Biophys J 2003;84:1031-7.

18. Brändén G, Pawate AS, Gennis RB, Brzezinski P. Controlled uncoupling and recoupling of proton pumping in cytochrome c oxidase. Proc Natl Acad Sci USA 2006;103:317-22.

19. Mulkidjanian AY, Herbele J, Cherepanov DA. Protons @ interfaces: Implications for biological energy conservation. Biochim Biophys Acta 2006;1757:913-30.

20. Agmon N, Gutman M. Bioenergetics: proton fronts on membranes, Nat Chem 2011;3:840-2.

21. Sandén T, Salomonsson L, Brzezinski P, Widengren J. Surface-coupled proton exchange of a membrane-bound proton acceptor. Proc Natl Acad Sci USA 2010;107:4129-34. 
22. Springer A, Hagen V, Cherepanov DA, Antonenko YN, Pohl P. Protons migrate along interfacial water without significant contributions from jumps between ionizable groups on the membrane surface. Proc Natl Acad Sci USA 2011;108:14461-6.

23. Medvedev ES, Stuchebrukhov AA. Mechanism of long-range proton translocation along biological membranes. FEBS Lett 2013;587:345-9.

24. Wolf MG, Grubmüller H, Groenhof G. Anomalous surface diffusion of protons on lipid membranes. Biophys J 2014;107:76-87.

25. Dilley RA. On why thylakoids energize ATP formation using either delocalized or localized proton gradients $-\mathrm{a} \mathrm{Ca}^{2+}$ mediated role in thylakoid stress responses. Photosynth Res 2004;80: 245-63.

26. Silverstein TP. An exploration of how the thermodynamic efficiency of bioenergetic membrane systems varies with c-subunit stoichiometry of $F_{1} F_{0}$ ATP synthases. J Bioenerg Biomembr 2014;46:229-41.

27. Öjemyr LN, Lee HJ, Gennis RB, Brzezinski P. Functional interactions between membranebound transporters and membranes. Proc Natl Acad Sci USA 2010;107:15763-7.

28. Öjemyr LN, von Ballmoos C, Faxen K, Svahn E, Brzezinski P. The membrane modulates internal proton transfer in cytochrome c oxidase. Biochemistry 2012;51:1092-100.

29. Rieger $\mathrm{B}$, Junge $\mathrm{W}$, Busch KB. Lateral $\mathrm{pH}$ gradient between OXPHOS complex IV and $\mathrm{F}_{0} \mathrm{~F}_{1}$ ATP-synthase in folded mitochondrial membranes. Nat Commun 2014;5:3103 (DOI: 10.1038/ncomms4103).

30. Klotzsch E, Smorodchenko A, Löfler L, Moldzio R, Parkinson E, Schütz GJ, et al. Superresolution microscopy reveals spatial separation of UCP4 and $\mathrm{F}_{0} \mathrm{~F}_{1}$-ATP synthase in neuronal mitochondria. Proc Natl Acad Sci USA 2015;112:130-5.

31. Elling FJ, Könneke M, Lipp JS, Becker KW, Gagen EJ, Hinrichs K-U. Effects of growth phase on the membrane lipid composition of the thaumarchaeon Nitrosopumilus maritimus and their implications for archaeal lipid distributions in the marine environment. Geochim Cosmochim Acta 2014;141:579-97.

32. Kellermann MY, Yoshinaga MY, Valentine RC, Wörmer L, Valentine DL. Thermodynamic ecology dictates the membrane lipid composition in haloarchaea (submitted).

33. Ames GF. Lipids of Salmonella typhimurium and Escherichia coli: structure and metabolism. J Bacteriol 1968;95:833-43. 
34. Clejan S, Krulwich TA, Mondrus KR, Seto-Young D. Membrane lipid composition of obligately and facultatively alkalophilic strains of Bacillus spp. J Bacteriol 1986;168:334-40.

35. Van Mooy BA, Rocap G, Fredricks HF, Evans CT, Devol AH. Sulfolipids dramatically decrease phosphorus demand by picocyanobacteria in oligotrophic marine environments. Proc Natl Acad Sci USA 2006;103:8607-12.

36. Wada H, Murata N. Lipids in Photosynthesis: essential and regulatory functions. Advances in Photosynthesis and Respiration, vol 30, Springer, Dordrecht, 2009.

37. Fleischer S, Rouser G, Fleischer B, Casu A, Kritchevsky GJ. Lipid composition of mitochondria from bovine heart, liver, and kidney. Lipid Res 1967;8:170-80.

38. Teissié J, Prats M, Soucaille P, Tocanne J-F. Evidence for conduction of protons along the interface between water and a polar lipid monolayer. Proc Natl Acad Sci USA 1985;82:321721.

39. Teissié J, Gabriel B, Prats M. Lateral communication by fast proton conduction: a model membrane study. Trends Biochem Sci 1993;18:243-6.

40. Haines TH, Dencher NA. Cardiolipin: a proton trap for oxidative phosphorylation. FEBS Lett 2002;528:35-9.

41. KocherginskyN. Acidic lipids, $\mathrm{H}^{+}$-ATPases, and mechanism of oxidative phosphorylation. Physico-chemical ideas 30 years after P. Mitchell's Nobel Prize award. Prog Biophys Mol Biol 2009;99:20-41.

42. Morelli AM, Ravera S, Calzia D, Panfoli I. Hypothesis of lipid-phase-continuity proton transfer for aerobic ATP synthesis. J Cereb Blood Flow Metab 2013;33:1838-42.

43. Schägger H. Respiratory chain supercomplexes of mitochondria and bacteria. Biochim Biophys Acta Bioenerg 2002;1555:154-9.

44. Stroh A, Anderka O, Pfeiffer K, Yagi T, Finel M, Ludwig B, et al. Assembly of respiratory complexes I, III, and IV into NADH oxidase supercomplex stabilizes complex I in Paracoccus denitrificans. J Biol Chem 2004;279:5000-7.

45. Dudkina V, Sunderhaus S, Braun HP, EBoekema EJ. Characterization of dimeric ATP synthase and cristae membrane ultrastructure from Saccharomyces and Polytomella mitochondria. FEBS Lett 2006;580:3427-32. 
46. Schäfer E, Seelert H, Reifschneider NH, Krause F, Dencher NA, Vonck J. Architecture of active mammalian respiratory chain supercomplexes. J Biol Chem 2006;281:15370-5.

47. Lenn T, Leake MC, Mullineaux CW. Clustering and dynamics of cytochrome bd-I complexes in the Escherichia coli plasma membrane in vivo. Mol Microbiol 2008;70:1397407.

48. Sousa PMF, Silva STN, Hood BL, Charro N, Carita JN, Vaz F, et al. Supramolecular organizations in the aerobic respiratory chain of Escherichia coli. Biochimie 2011;93:41825.

49. Liu L-N, Bryan SJ, Huang F, Yu J, Nixon PJ, Rich PR, et al. Control of electron transport routes through redox-regulated redistribution of respiratory complexes. Proc Natl Acad Sci USA 2012;109:11431-6.

50. Erhardt H, Dempwolff F, Pfreundschuh M, Riehle M, Schäfer C, Pohl T, et al. Organization of the Escherichia coli aerobic enzyme complexes of oxidative phosphorylation in dynamic domains within the cytoplasmic membrane. Microbiol Open 2014;3:316-26.

51. Llorente-Garcia I, Lenn T, Erhardt H, Harriman OL, Liu L-N, Robson A, et al. Singlemolecule in vivo imaging of bacterial respiratory complexes indicates delocalized oxidative phosphorylation. Biochim Biophys Acta 2014,1837:811-24.

52. Siegenthaler P. Molecular organization of acyl lipids in photosynthetic membranes of higher plants, in: Siegenthaler P, Murata N (Eds.). Lipids in photosynthesis: structure, function and genetics, Kluwer Academic Publishers, Dordrecht, pp. 119-44, 1998.

53. Field VB, Behrenfeld MJ, Randerson JT, Falkowski P. Primary production of the biosphere: integrating terrestrial and oceanic components. Science 1998;281:237-40.

54. Somerville C, Browse J, Jaworski JG. Lipids. In: Buchanan BB, Gruissem W, Jones R (Eds.). Biochemistry and molecular biology of plants, American Society of Plant Physiologists. Rockville, pp. 456-527, 2000.

55. Dowhan W, Mileykovskaya E, Bogdanov M. Diversity and versatility of lipid- protein interactions revealed by molecular genetic approaches. Biochim Biophys Acta 2004;1666:19_39.

56. DeChavigny A, Heacock PN, Dowhan W. Sequence and inactivation of the pss gene of Escherichia coli. Phosphatidylethanolamine may not be essential for cell viability. J Biol Chem 1991;266:5323-32. 
57. Xie J, Bogdanov M, Heacock P, Dowhan W. Phosphatidylethanolamine and monoglucosyldiacylglycerol are interchangeable in supporting topogenesis and function of the polytopic membrane protein lactose permease. J Biol Chem 2006;281:19172-8.

58. Wikström M, Xie J, Bogdanov M, Mileykovskaya E, Heacock P, Wieslander $\AA$, et al. Monoglucosyldiacylglycerol, a foreign lipid, can substitute for phosphatidylethanolamine in essential membrane-associated functions in Escherichia coli. J Biol Chem 2004;279:1028493.

59. Wikström M, Kelly AA, Georgiev A, Eriksson HM, Klement MR, Bogdanov M, et al. Lipidengineered Escherichia coli membranes reveal critical lipid headgroup size for protein function. J Biol Chem 2009;284:954-65.

60. Van Mooy BAS, Fredricks HF, Pedler BE, Dyhrman ST, Karl DM, Lomas MW, et al. Phytoplankton in the ocean use non-phosphorus lipids in response to phosphorus scarcity. Nature 2009;458:69-72.

61. Dörmann P, Benning C. Galactolipids rule in seed plants. Trends Plant Sci 2002;7:112-118.

62. Jones MR. Lipids in photosynthetic reaction centres: Structural roles and functional holes. Prog Lipid Res 2007;46:56-87.

63. Dörmann P, Hoffmann-Benning S, Balbo I, Benning C. Isolation and characterization of an Arabidopsis mutant deficient in the thylakoid lipid digalactosyl diacylglycerol. Plant Cell 1995;7:1801-10.

64. Jarvis SP, Uchihashi $\mathrm{T}$, Ishida $\mathrm{T}$, Tokumoto H, Nakayama Y. Local solvation shell measurement in water using a carbon nanotube probe. J Phys Chem B 2000;104:6091-4.

65. Hölzl G, Witt S, Kelly AA, Zähringer U, Warnecke D, Dörmann P, et al. Functional differences between galactolipids and glucolipids revealed in photosynthesis of higher plants. Proc Natl Acad Sci USA 2006;103:7512-7.

66. Awai K, Ohta H, Sato N. Oxygenic photosynthesis without galactolipids. Proc Natl Acad Sci USA 2014;111:13571-5.

67. $\mathrm{Yu} \mathrm{B}$, Benning $\mathrm{C}$. Anionic lipids are required for chloroplast structure and function in Arabidopsis. Plant J 2003;36:762-70.

68. Raetz CR, Dowhan W. Biosynthesis and function of phospholipids in Escherichia coli. J Biol Chem 1990;265:1235-8. 
69. Tocanne J-F, Teissié J. Ionization of phospholipids and phospholipid-supported interfacial lateral diffusion of protons in membrane model systems. Biochim Biophys Acta 1990;1031:111-42.

70. Kates M, Syz JY, Gosser D, Haines TH. pH-dissociation characteristics of cardiolipin and its 2"-deoxy analogue. Lipids 1993;28:877-82.

71. Khalifat N, Puff N, Bonneau S, Fournier JB, Angelova MI. Membrane deformation under local pH gradient: mimicking mitochondrial cristae dynamics. Biophys J 2008;95: 4924-33.

72. Khalifat N, Fournier JB, Angelova MI, Puff N. Lipid packing variations induced by $\mathrm{pH}$ in cardiolipin-containing bilayers: the driving force for the cristae-like shape instability. Biochim Biophys Acta 2011;1808:2724-33.

73. Khalifat N, Rahimi M, Bitbol AF, Seigneuret M, Fournier JB, Puff N, et al. Interplay of packing and flip-flop in local bilayer deformation. How phosphatidylglycerol could rescue mitochondrial function in a cardiolipin-deficient yeast mutant. Biophys J 2014;107:879-90.

74. Boggs JM. Intermolecular hydrogen bonding between lipids: influence on organization and function of lipids in membranes. Can J Biochem 1980;58:755-70.

75. Boggs JM. Lipid intermolecular hydrogen bonding: influence on structural organization and membrane function. Biochim Biophys Acta 1987;906:353-404.

76. Stewart LC, Kates M, Yang PW, Mantsch HH. Intra- and inter-molecular hydrogen bonding in diphytanyl glycerol phospholipids: an infrared spectroscopic investigation. Biochem Cell Biol 1990;68:266-73.

77. Lopez CF, Nielsen SO, Klein ML, Moore PBJ. Hydrogen bonding structure and dynamics of water at the dimyristoylphosphatidylcholine lipid bilayer surface from a molecular dynamics simulation. Phys Chem B 2004;108:6603-6610.

78. Milhaud J. New insights into water-phospholipid model membrane interactions. Biochim Biophys Acta 2004;1663:19-51.

79. Jaselskis B, Moore CE, von Smolinsk A. Theodor von Grotthuss (1785-1822) - A trail blazer. Bull Hist Chem 2007;32:119-28.

80. Kamekura M, Kates M. Structural diversity of membrane lipids in members of Halobacteriaceae. Biosci Biotechnol Biochem 1999;63:969-72.

81. Cohen S, Oren A, Shilo M. The divalent cation requirement of Dead Sea halobacteria. Arch Microbiol 1983;136:184-90. 
82. Wang X, Lv B, Cai G, Fu L, Wu Y, Wang X, et al. A proton shelter inspired by the sugar coating of acidophilic archaea. Sci Rep 2012;2:829 (doi:10.1038/srep00892).

83. Valentine RC, Valentine DL. Omega-3 fatty acids in cellular membranes: a unified concept. Prog Lipid Res 2004;43:383-402.

84. Valentine RC, Valentine DL. Omega-3 fatty acids and the DHA principle, Taylor and Francis Group, Boca Raton, 2009.

85. Henderson R, Jubb JS, Whytock S. Specific labelling of the protein and lipid on the extracellular surface of the purple membrane. J Mol Biol 1978;123:259-74.

86. Weik M, Patzelt H, Zaccai G, Oesterhelt D. Localization of glycolipids in membranes by in vivo labeling and neutron diffraction. Mol Cell 1998;1:411-9.

87. Gulik A, Luzzati V, De Rosa M, Gambacorta A. Tetraether lipid components from a thermoacidophilic archaebacterium: chemical structure and physical polymorphism. J Mol Biol 1998;210:429-35.

88. Myers VB, Haydon DA. Ion transfer across lipid membranes in the presence of gramicidin A. II. The ion selectivity. Biochim Biophys Acta 1972;274:313-22.

89. Onsager L. The motion of ions: principles and concepts. Science 1969;166:1359-64.

90. Nagle JF, Morowitz HJ. Molecular mechanisms for proton transport in membranes. Proc Natl Acad Sci USA 1978;75:298-302.

91. Deamer DW, Nichols JW. Proton flux mechanisms in model and biological membranes. J Membr Biol 1989;107:91-103.

92. DeCoursey TE. Voltage-gated proton channels and other proton transfer pathways. Physiol Rev 2003;83:475-9.

93. Cukierman S. Et tu, Grotthuss! and other unfinished stories. Biochim Biophys Acta 2006; 1757:876-85.

94. Wraight CA. Chance and design: proton transfer in water, channels and bioenergetic proteins. Biochim Biophys Acta 2006;1757:886-912.

95. Ball P. Water as an active constituent in cell biology. Chem Rev 2008; 108:74-108.

96. DeCoursey TE, Hosler J. Philosophy of voltage-gated proton channels. J R Soc Interface 2014;11:20130799 (doi:10.1098/rsif.2013.0799).

97. Cevc G. Membrane electrostatics. Biochim Biophys Acta 1990;1031:311-82. 
98. Berkowitz ML, Bostick DL, Pandit S. Aqueous solutions next to phospholipid membrane surfaces: insights from simulations. Chem Rev 2006;106:1527-39.

99. Brewer ML, Schmitt UW, Voth GA. The formation and dynamics of proton wires in channel environments. Biophys J 2001;80:1691-702.

100. Gutman M, Nachliel E. The dynamics of proton exchange between bulk and surface groups. Biochim Biophys Acta 1995;1231:123-38.

101. Kasianowicz J, Benz R, McLaughlin S. How do protons cross the membrane-solution interface? Kinetic studies on bilayer membranes exposed to the protonophore S-13 (5-chloro3-tert-butyl-2'-chloro-4' - nitrosalicylanilide). J Membr Biol 1987;95:73-89.

102. Medvedev ES, Stuchebrukhov AA. Mechanisms of generation of local $\Delta \mathrm{pH}$ in mitochondria and bacteria. Biochemistry 2014;79:425-34.

103. Haines TH. Do sterols reduce proton and sodium leaks through lipid bilayers? Prog Lipid Res 2001;40:299-324.

104. Paula S, Volkov AG, van Hoek AN, Haines TH, Deamer DW. Permeation of protons, potassium ions, and small polar molecules through phospholipid bilayers as a function of membrane thickness. Biophys J 1996;70:339-48.

105. Walker JE. The ATP synthase: the understood, the uncertain and the unknown. Biochem Soc Trans 2013;41:1-16.

106. Boyer PD. The ATP synthase - a splendid molecular machine. Annu Rev Biochem 1997;66:717-49.

107. von Ballmoos C, Cook GM, Dimroth P. Unique rotary ATP synthase and its biological diversity. Annu Rev Biophys 2008;37:43-64.

108. Takamori S, Holt M, Stenius K, Lemke EA, Grønborg M, Riedel D, et al. Molecular anatomy of a trafficking organelle. Cell 2006;127:831-46.

109. Hassel B, Dingledine K. Glutamate. In: Siegel G, Albers RW, Brady ST, Price D (Eds.). Basic neurochemistry: molecular, cellular and medical aspects. 7th ed., Elsevier Academic Press, pp. 267-90, 2006.

110. Michaelson DM, Angel I. Determinationof $\Delta \mathrm{pH}$ in cholinergic synaptic vesicles: its effect on storage and release of acetylcholine. Life Sci 1980;27:39-44.

111. Neidhardt FC. Escherichia coli and Salmonella: molecular and cellular biology. ASM Press, Washington DC, 1996. 
112. Milo R, Phillips R. Cell biology by the numbers, Garland press, 2015.

113. Tikhonov AN. Energetic and regulatory role of proton potential in chloroplasts. Biochemistry 2012;77:956-74.

114. Ueno H, Suzuki T, Kinosita Jr K, Yoshida M. ATP-driven stepwise rotation of $F_{0} F_{1}-A T P$ synthase. Proc Natl Acad Sci USA 2005;102:1333-8.

115. Farmer IS, Jones CW. The energetics of Escherichia coli during aerobic growth in continuous culture. Eur J Biochem 1976;67:115-22.

116. Reshes G, Vanounou S, Fishov I, Feingold M. Timing the start of division in E. coli: a single-cell study. Phys Biol 2008;5:046001 (doi: 10.1088/1478-3975/5/4/046001).

117. Tran QH, Unden G. Changes in the proton potential and the cellular energetics of Escherichia coli during growth by aerobic and anaerobic respiration or by fermentation. Eur $\mathrm{J}$ Biochem 1998;251:538-43.

118. Medvedev ES, Stuchebrukhov AA. Kinetics of proton diffusion in the regimes of fast and slow exchange between the membrane surface and the bulk solution. J Math Biol 2006;52:209-34.

119. Vilčiauskas L, Tuckerman ME, Bester G, Paddison SJ, Kreuer K-D The mechanism of proton conduction in phosphoric acid. Nat Chem 2012;4:461-6.

120. Sowers KR, Gunsalus RP. Plasmid DNA from the acetotrophic methanogen Methanosarcina acetivorans. J Bacteriol 1988;170:4979-82.

121. Schmidt JE, Macario AJL, Ahring BK, Macario EC. Effect of magnesium on methanogenic subpopulations in a thermophilic acetate-degrading granular consortium. Appl Environ Microbiol 1992;58:862-8.

122. Salzberg LI, Helmann JD. Phenotypic and transcriptomic characterization of Bacillus subtilis mutants with grossly altered membrane composition. J Bacteriol 2008;190:7797-807.

123. Nikaido H. Molecular basis of bacterial outer membrane permeability revisited. Microbiol Mol Biol Rev 2003;67:593-656.

124. Edlund C, Nord CE. Effect on the human normal microflora of oral antibiotics for treatment of urinary tract infections. J Antimicrob Chemother 2000;46:41-8.

125. Suarez RK. Oxygen and the upper limits to animal design and performance. J Exp Biol 1998;201:1065-72. 
126. Willey JM, Sherwood LM, Woolverton CJ. Microbial growth. In: Prescott's Microbiology, 8th edition, McGraw Hill Higher Education, pp. 155-189, 2011.

127. Kates M. Membrane lipids of Archaea. In: Kates M, Kushner DJ, Matheson AT (Eds.). New comprehensive biochemistry, Elsevier, Amsterdam, pp. 261-95, 1993.

128. Koga Y, Morii H. Recent advances in structural research on ether lipids from archaea including comparative and physiological aspects. Biosci Biotechnol Biochem 2005;69:201934.

129. Valentine DL. Adaptations to energy stress dictate the ecology and evolution of the Archaea. Nat Rev Microbiol 2007;5:316-23.

130. Essen L, Siegert R, Lehmann WD, Oesterhelt D. Lipid patches in membrane protein oligomers: crystal structure of the bacteriorhodopsin-lipid complex. Proc Natl Acad Sci USA 1998;95:11673-8.

131. Wikström M, Sharma V, Kaila VRI, Hosler JP, Hummer G. New perspectives on proton pumping in cellular respiration. Chem Rev 2015;115:2196-221.

132. Tuller G, Hrastnik C, Achleitner G, Schiefthaler U, Klein F, Daum G. YDL142c encodes cardiolipin synthase (Cls1p) and is non-essential for aerobic growth of Saccharomyces cerevisiae. FEBS Lett 1998;421:15-8.

133. Matsumoto K. Dispensable nature of phosphatidylglycerol in Escherichia coli: dual roles of anionic phospholipids. Mol Microbiol 2001;39:1427-33.

134. Liu J, Ryabichko S, Bogdanov M, Fackelmayer OJ, Dowhan W, Krulwich TA. Cardiolipin is dispensable for oxidative phosphorylation and non-fermentative growth of alkaliphilic Bacillus pseudofirmus OF4. J Biol Chem 2014;289:2960-71.

135. Chang SC, Heacock PN, Clancey CJ, Dowhan W. The PEL1 gene (renamed PGS1) encodes the phosphatidylglycerophosphate synthase of Saccharomyces cerevisiae. J Biol Chem 1998;273:9829-36.

136. Jiang F, Ryan MT, Schlame M, Zhao M, Gu ZM, Klingenberg M, et al. Absence of cardiolipin in the crd1 null mutant results in decreased mitochondrial membrane potential and reduced mitochondrial function. J Biol Chem 2000;275:22387-94.

137. Finkelstein A, Andersen OS. The gramicidin A channel: a review of its permeability characteristics with special reference to the single-file aspect of transport. J Memb Biol 1981;39:155-71. 
138. van de Vossenberg JLCM, Ubbink-Kok T, Elferink MGL, Driessen AJM, Konings WN. Ion permeability of the cytoplasmic membrane limits the maximum growth temperature of bacteria and archaea. Mol Microbiol 1995;18:925-32.

139. Oesterhelt D, Stoeckenius W. Functions of a new photoreceptor membrane. Proc Natl Acad Sci USA 1973;70:2853-7.

140. Oesterhelt D, Stoeckenius W. Rhodopsin-like protein from the purple membrane of Halobacterium halobium. Nature New Biol 1971;233:149-52.

141. Henderson R. The purple membrane from Halobacterium halobium. Annu Rev Biophys Bioeng 1977;6:87-109.

142. Kushwaha SC, Kates M, Martin W Characterization and composition of the purple and red membrane from Halobacterium cutirubrum. Can J Biochem 1975;53:284-92.

143. Henderson R, Unwin PNT. Three-dimensional model of purple membrane obtained by electron microscopy. Nature 1975;257:28-32.

144. Corcelli A, Colella M, Mascolo G, Fanizzi FP, Kates M. A novel glycolipid and phospholipid in the purple membrane. Biochemistry 2000;39:3318-26.

145. Grüber G, Manimekalai MS, Mayer F, Müller V. ATP synthases from archaea: the beauty of a molecular motor. Biochim Biophys Acta 2014;1837:940-52.

146. Johnson AS, van Horck S, Lewis PJ. Dynamic localization of membrane proteins in Bacillus subtilis. Microbiology 2004;150:2815-24.

147. Peng LW, Shimizu H, Shikanai T. The chloroplast NAD(P)H dehydrogenase complex interacts with photosystem I in Arabidopsis. J Biol Chem 2008;283:34873-9.

148. Davies KM, Daum B. Role of cryo-ET in membrane bioenergetics research. Biochem Soc Trans 2013;41:1227-34.

149. Daum B, Nicastro D, Austin 2nd J., McIntosh JR, Kühlbrandt W. Arrangement of photosystem II and ATP synthase in chloroplast membranes of spinach and pea. Plant Cell 2010;22:1299-312.

150. Kramer DM, Sacksteder CA, Cruz JA. How acidic is the lumen? Photosynth Res 1999;60:151-163.

151. Unitt MD, Harwood JL. Sidedness studies of thylakoid phosphatidylglycerol in higher plants. Biochem J 1985;228:707-11. 
152. Rawyler A, Unitt MD, Giroud C, Davies H, Mayor JP, Harwood JL, et al. The transmembrane distribution of galactolipids in chloroplast thylakoids is universal in a wide variety of temperate climate plants. Photosynth Res. 1987;11:3-13.

153. Kramer DM, Cruz JA, Kanazawa A. Balancing the central roles of the thylakoid proton gradient. Trends Plant Sci 2003;8:27-32.

154. Vogel F, Bornhövd C, Neupert W, Reichert AS. Dynamic subcompartmentalization of the mitochondrial inner membrane. J Cell Biol 2006;175:237-47.

155. Strauss M, Hofhaus G, Schroder RR, Kühlbrandt W. Dimer ribbons of ATP synthase shape the inner mitochondrial membrane. EMBO J. 2008;27:1154-60.

156. Davies KM, Strauss M, Daum B, Kief JH, Osiewacz HD, Rycovska A, et al. Macromolecular organization of ATP synthase and complex I in whole mitochondria. Proc Natl Acad Sci USA 2011;108:14121-6.

157. Nemoto N, Shida Y, Shimada H, Oshima T, Yamagishi A. Characterization of the precursor of tetraether lipid biosynthesis in the thermoacidophilic archaeon Thermoplasma acidophilum. Extremophiles 2003;7:235-43.

158. Golyshina OV, Yakimov MM, Lünsdorf H, Ferrer M, Nimtz M, Timmis KN, et al. Acidiplasma aeolicum gen. nov., sp. nov., a euryarchaeon of the family Ferroplasmaceae isolated from a hydrothermal pool, and transfer of Ferroplasma cupricumulans to Acidiplasma cupricumulans comb. nov. Int J Syst Evol Microbiol 2009;59:2815-23.

159. Sturt HF, Summons RE, Smith K, Elvert M, Hinrichs K-U. Intact polar membrane lipids in prokaryotes and sediments deciphered by high-performance liquid chromatography electrospray ionization multistage mass spectrometry - new biomarkers for biogeochemistry and microbial ecology. Rapid Comm Mass Spectrom 2004;18:617-28.

160. Sprott GD, Agnew BJ, Patel GB. Structural features of ether lipids in the archaeobacterial thermophiles Pyrococcus furiosus, Methanopyrus kandleri, Methanothermus fervidus, and Sulfolobus acidocaldarius. Can J Microbiol 1997;435:467-76.

161. Meador TB, Gagen EJ, Loscar ME, Goldhammer T, Yoshinaga MY, Wendt J, et al. Thermococcus kodakarensis modulates its polar membrane lipids and elemental composition according to growth stage and phosphate availability. Front Microbiol 2014;5 (doi: 10.3389/fmicb.2014.00010). 
162. Kates M. Membrane lipids of Archaea, in: Kates M, Kushner DJ, Matheson AT (Eds.), New comprehensive biochemistry, Elsevier, Amsterdam, 1993, pp. 261-295.

163. Yamauchi Y, Minegishi H, Echigo A, Shimane Y, Shimoshige H, Kamekura M, et al. Halarchaeum salinum sp. nov., a moderately acidophilic haloarchaeon isolated from commercial sea salt. Int J Syst Evol Microbiol 2013;63:1138-42.

164. Kamekura M, Dyall-Smith ML, Upasani V, Ventosa A, Kates M. Diversity of alkaliphilic halobacteria: proposals for transfer of Natronobacterium vacuolatum, Natronobacterium magadii, and Natronobacterium pharaonis toHalorubrum, Natrialba, and Natronomonas gen. nov., respectively, as Halorubrum vacuolatum comb. nov., Natrialba magadii comb. nov., and Natronomonas pharaonis comb. nov., respectively. Int J Syst Bacteriol 1997;47:853-7.

165. Sprott GD, Dicaire CJ, Patel GB. The ether lipids of Methanosarcina species, compared by fast atom bombardment mass spectrometry. Can J Microbiol 1994;40:837-43.

166. Donato MM, Seleiro EA, Costa MS. Polar lipid and fatty acid composition of strains of the genus Thermus. Syst Appl Microbiol 1990;13:234-9.

167. Yang YL, Yang FL, Jao SC, Chen MY, Tsay SS, Zou W, et al. Structural elucidation of phosphoglycolipids from strains of the bacterial thermophiles Thermus and Meiothermus. J Lipid Res 2006;47:1823-32.

168. Wiegel J, Ljungdahl LG. Thermoanaerobacter ethanolicus gen. nov., spec. nov., a new, extreme thermophilic, anaerobic bacterium. Arch Microbiol 1981;128:343-8.

169. Stohr R, Waberski A, Volker H, Tindall BJ, Thomm M. Hydrogenothermus marinus gen. nov., sp. nov., a novel thermophilic hydrogen-oxidizing bacterium, recognition of Calderobacterium hydrogenophilum as a member of the genus Hydrogenobacter and proposal of the reclassification of Hydrogenobacter acidophilus as Hydrogenobaculum acidophilum gen. nov., comb. nov., in the phylum 'Hydrogenobacter/Aquifex'. Int J Syst Evol Microbiol 2001;51:1853-62.

170. Itoh T, Yamonoi K, Kudo T, Ohkuma M, Takashina T. Aciditerrimonas ferrireducens gen. nov., sp. nov., an iron-reducing thermoacidophilic actinobacterium isolated from a solfataric field. Int J Syst Evol Microbiol 2011;61:1281-5.

171. Wichlacz PL, Unz RF, Langworthy TA. Acidiphilium angustum sp. nov., Acidiphilium facilis sp. nov., and Acidiphilium rubrum sp. nov.: acidophilic heterotrophic bacteria isolated from acidic coal mine drainage. Int J Syst Evol Microbiol 1986;36:197-201. 
172. Ma Y, Xue Y, Grant WD, Collins NC, Duckworth AW, van Steenbergen RP, et al. Alkalimonas amylolytica gen. nov., sp. nov., and Alkalimonas delamerensis gen. nov., sp. nov., novel alkaliphilic bacteria from soda lake lakes in China and East Africa. Extremophiles 2004;8:193-200.

173. Lee K, Choo Y-J, Giovannoni SJ, Cho J-C. Maritimibacter alkaliphilus gen. nov., sp. nov., a genome-sequenced marine bacterium of the Roseobacter clade in the order Rhodobacterales. Int J Syst Evol Microbiol 2007;57:1653-8.

174. Berendes F, Gottschalk G, Heine-Dobbernack E, Moore ERB, Tindall BJ. Halomonas desiderata sp. nov., a new alkaliphilic, halotolerant and denitrifying bacterium isolated from a municipal sewage works. System Appl Microbiol 1996;19:158-67.

175. Khmelenina VN, Kalyuzhneya MG, Starostina NG, Suzina NE, Trotsenko YA. Isolation and characterization of halotolerant alkaliphilic methanotrophic bacteria from Tuva soda lakes. Curr Microbiol 1997;35:257-61.

176. Yakimov MM, Giuliano L, Chernikova TN, Gentile G, Abraham WR, Lünsdorf H, et al. Alcalilimnicolahalodurans gen. nov., sp. nov., an alkaliphilic, moderately halophilic and extremely halotolerant bacterium, isolated from sediments of soda-depositing Lake Natron, East Africa Rift Valley. Int J Syst Evol Microbiol 2001;51:2133-43.

177. Romano I, Giordano A, Lama L, Nicolaus B, Gambacorta A. Halomonas campaniensis sp. nov., a haloalkaliphilic bacterium isolated from a mineral pool of Campania region, Italy. Syst Appl Microbiol 2005;28:610-8.

178. Duckworth AW, Grant S, Grant WD, Jones BE, Meijer D. Dietzia natronolimnaios sp. nov., a new member of the genus Dietzia isolated from an East African soda lake. Extremophiles 1998;2:359-66.

179. Ntougias S, Russell NJ. Alkalibacterium olivoapovliticus gen. nov., sp. nov., a new obligately alkaliphilic bacterium isolated from edible-olive wash-waters. Int J Syst Evol Microbiol 2001;51:1161-70.

180. Caccamo D, Gugliandolo C, Stackebrandt E, Maugeri TL. Bacillus vulcani sp. nov., a novel thermophilic species isolated from a shallow marine hydrothermal vent. Int J Syst Evol Microbiol 2000;50:2009-12. 
181. Langworthy TA, Mayberry WR, Smith PF. A sulfonolipid and novel glucosamidyl glycolipids from the extreme thermoacidophile Bacillus acidocaldarius. Biochim Biophys Acta 1976;431:550-69.

182. Albert RA, Archambault J, Rosselló-Mora R, Tindall BJ, Matheny M. Bacillus acidicola sp. nov., a novel mesophilic, acidophilic species isolated from acidic Sphagnum peat bogs in Wisconsin. Int J Syst Evol Microbiol 2005;55:2125-30.

183. Antunes A, Rainey FA, Nobre MF, Schumann P, Ferreira AM, Ramos A, et al. Leuconostoc ficulneum sp. nov., a novel lactic acid bacterium isolated from a ripe fig, and reclassification of Lactobacillus fructosus as Leuconostoc fructosum comb. nov. Int J Syst Evol Microbiol 2002;52:647-55.

184. Ying J-Y, Wang B-J, Dai X, Yang S-S, Liu S-J, Liu Z-P. Wenxinia marina gen. nov., sp. nov., a novel member of the Roseobacter clade isolated from oilfield sediments of the South China Sea. Int J Syst Evol Microbiol 2007;57:1711-6.

185. Abraham WR, Strömpl C, Vancanneyt M, Bennasar A, Swings J, Lünsdorf H, et al. Woodsholea maritima gen. nov., sp. nov., a marine bacterium with a low diversity of polar lipids. Int J Syst Evol Microbiol 2004;54:1227-34.

186. Finster K, Liesack W, Tindall BJ. Sulfurospirillum arcachonense sp. nov., a new microaerophilic sulfur-reducing bacterium. Int J Syst Evol Microbiol 1997;47:1212-7.

187. Wagner-Döbler I, Rheims H, Felske A, Pukall R, Tindall BJ. Jannaschia helgolandensis gen. nov., sp. nov., a novel abundant member of the marine Roseobacter clade from the North Sea. Int J Syst Evol Microbiol 2003;53:731-8.

188. Glaeser SP, McInroy JA, Busse HJ, Kampfer P. Pseudogracilibacillus auburnensis gen. nov., sp. nov., isolated from the rhizosphere of Zea mays. Int J Syst Evol Microbiol 2014;64:2442-8.

189. Ward DM, Panke S, Klöppel K-D, Christ R, Fredrickson H. Complex polar lipids of a hot spring cyanobacterial mat and its cultivated inhabitants. Appl Environ Microbiol 1994;60:3358-67.

190. Nichols BW, Harris RV, James T. The lipid metabolism of blue-green algae, Biochem. Biophys Res Commun 1965;20:256-62. 
191. Benning C, Huang Z-H, Gage DA. Accumulation of a novel glycolipid and a betaine lipid in cells of Rhodobacter sphaeroides grown under phosphate limitation. Arch Biochem Biophys 1995;327:103-111.

192. Romano I, Bellitti ML, Nicolaus B, Lama L, Manca MC, Pagnotta M, et al. Lipid profile: a useful chemotaxinomic marker for classification of a new cyanobacterium in the Spirulina genus. Phytochemistry 2000;54:289-94.

193. Selstam E, Campbell D. Membrane lipid composition of the unusual cyanobacterium Gloeobacter violaceus sp. PCC 7421, which lacks sulfoquinovosyl diacylglycerol. Arch Microbiol 1996;166:132-5.

194. Mombelli E, Morris RJ, Taylor W, Fraternali F. Hydrogen-bonding propensities of sphingomyelin in solution and in a bilayer assembly: a molecular dynamics study. Biophys J 2003;84:1507-17.

195. Ward DM, Ferris MJ, Nold SC, Bateson MM. A natural view of microbial biodiversity within hot spring cyanobacterial mat communities. Microbiol Mol Biol Rev 1998;62:135370.

196. Takai K, Nakamura K, Toki T, Tsunogai U, Miyazaki M, Miyazaki J, et al. Cell proliferation at 122 degrees $\mathrm{C}$ and isotopically heavy $\mathrm{CH}_{4}$ production by a hyperthermophilic methanogen under high-pressure cultivation. Proc Natl Acad Sci USA 2008;105:10949-54.

197. Oren A. Molecular ecology of extremely halophilic Archaea and Bacteria. FEMS Microbiol Ecol 2002;39:1-7.

198. Nishiyama Y, Langan P, Chanzy H. Crystal structure and hydrogen-bonding system in cellulose I $\beta$ from synchrotron X-ray and neutron fiber diffraction. J Am Chem Soc 2002; 124:9074-82.

199. Rinaudo M. Chitin and chitosan: Properties and applications. Prog Polym Sci 2006;31:60332.

200. Einbu A, Naess SN, Elgsaeter A, Vårum KM. Solution properties of chitin in alkali. Biomacromolecules 2004;5:2048-54.

201. Aziz EF, Ottosson N, Faubel M, Hertel IV, Winter B. Interaction between liquid water and hydroxide revealed by core-hole de-excitation. Nature 2008;455:89-91.

202. Krulwich TA, Sachs G, Padan E. Molecular aspects of bacterial pH sensing and homeostasis. Nat Rev Microbiol 2011;9:330-43. 
203. Albers SV, Meyer BH. The archaeal cell envelope. Nat Rev Microbiol 2011;9:414-26.

204. Hoiczyk E, Hansel A. Cyanobacterial cell walls: news from an unusual prokaryotic envelope. J Bacteriol 2000;182:1191-9.

205. Grant WD, Mwatha WE, Jones BE. Alkaliphiles: ecology, diversity and applications, FEMS Microbiol Rev 1990;75:255-70.

206. Edison AS. Linus Pauling and the planar peptide bond. Nat Struct Biol 2001;8:201-2.

207. Stillinger FH. Water revisited. Science 1980;209:451-7. 
Table 1. Distribution of phospho- and/or glyco-glycerolipids in energy-transducing membranes. $\mathrm{a}=$ anionic, $\mathrm{z}=$ zwitterionic, Phos = phospholipids, $\mathrm{SulfG}=$ sulfoglycolipids, Glyco $=$ glycolipids, Ref. $=$ references.

\begin{tabular}{|c|c|c|c|c|c|}
\hline Cell/Organelle & a-Phos & z-Phos & a-SulfG & Glyco & Ref. \\
\hline $\begin{array}{l}\text { Nitrosupumilus } \\
\text { maritimus }\end{array}$ & 4 & & & 96 & 31 \\
\hline $\begin{array}{l}\text { Halobacterium } \\
\text { salinarum }\end{array}$ & 75 & & & 15 & 32 \\
\hline Escherichia coli & 22 & 78 & & & 33 \\
\hline Bacillus subtilis* & 74 & 12 & & 6 & 34 \\
\hline Synechococcus WH8103 & 3 & & 52 & 44 & 35 \\
\hline Prochlorococcus MED4 & 2 & & 66 & 32 & 35 \\
\hline Chloroplast (spinach) & 11 & 4.5 & 6.5 & 78 & 36 \\
\hline $\begin{array}{l}\text { Mitochondria (bovine } \\
\text { heart) }\end{array}$ & 24 & 76 & & & 37 \\
\hline
\end{tabular}

\section{FIGURE CAPTIONS}

Figure 1. Structures of phospho- and glyco-glycerolipids in the three domains of life. (A) Major characteristics of archaeal lipids relative to bacterial and eukaryal lipids. Note that archaeal polar lipids are ether-linked to side chains composed of isoprenoids, whereas bacterial and eukaryal polar lipids are ester-linked to side chains most often composed of fatty acids. (B) Phospholipids are intrinsically charged. The attached functional group to the phosphate moiety (e.g. glycerol, ethanolamine) determines the final charge of the phospholipid. These lipids are generally anionic (in red) or zwitterionic (in green). Glycolipids are most often neutral (in gray), but may also display negative charge as the sulfolipids (in red). Sugar moieties can vary greatly in composition (e.g. galactose, glucose). Glycolipids may also carry charged functional groups such as the sulfated glycolipids, which are anionic. $\mathrm{PA}=$ phosphatidic acid; $\mathrm{PG}=$ phosphatidylglycerol; $\mathrm{CL}=$ cardiolipin; $\mathrm{SQ}=$ sulfoquinovosyl; $\mathrm{PE}=$ phosphatidylethanolamine; $\mathrm{PC}=$ phosphatidylcholine; $\mathrm{G}=\mathrm{gly} \operatorname{cosyl}$.

Figure 2. Membrane adaptation in archaea and bacteria to toxic levels of environmental acidity includes placement of glycolipids on the outer leaflet of the membrane surface. (A) This 
membrane synthesized by Wang and colleagues [82] shows how H-bonding of polyhydroxyl groups of sugar residues forms a lattice that might protect cells against damage by extremely low $\mathrm{pH}$ (acidity). These scientists used nanochemical methods to build a model sugar lattice whose H-bonded molecular architecture blocked diffusion of $\mathrm{H}^{+}$(hydronium ions, $\mathrm{H}_{3} \mathrm{O}^{+}$). (B) We have modified their model to explain how long-distance proton circulation may occur within glycolipids tethered by H-bonds on membranes surfaces such as in photosynthetic membranes. The focus here is on sugar headgroups in mediating proton transfer. However, it is important to recall that the often highly unsaturated tails of glycolipids represent by far the largest pool of membrane lipids in the biosphere. The conformation dynamics of the tails enables shuttling of electron carriers through the membrane bilayer [83, 84].

Figure 3. The hypothesized hyducton model. (A) Lipids comprising membrane surfaces are attached to each other via H-bonds, forming a narrow lattice with a minuscule volume (the hyducton), similar to the tethered glycolipids in Fig. 2. Protons attached to anionic lipids are in position to participate in proton circulation. Given the small numbers of protons in circulation, any change in proton concentration on the membrane surface will enable a net flow of protons from anionic headgroups to the water contained in the hyducton (red dotted line). (B) Protons are transported by a von Grotthuß mechanism, i.e. protons hopping through H-bonded water molecules contained in the hyducton. By giving up protons for circulation, anionic lipids are again free to accept available protons.

Figure 4. Proton arithmetic using a cell of E. coli as a model*. (A) Differences in volume between cytoplasm and the hyducton. (B) Variation in the number of protons available in the cytoplasm and the hyducton according to $\mathrm{pH}$ values. * Parameters used for calculation: cell dimension (0.5 and $2 \mu \mathrm{m}$ in width and length, respectively); $2.2 \times 10^{7}$ total polar lipids [111]; 15 water molecules per lipid $[77,98]$; volume of a water molecule ( $3 \times 10^{-26} \mathrm{~L}$; [112]); Avogadro's number $\left(6.02 \times 10^{23}\right)$.

Figure 5. Electron micrograph of mitochondria. (A) Liver mitochondrion displaying a dozen of cristae structures in its matrix (courtesy of Daniel S. Friend). (B) Hummingbird breast muscle mitochondrion showing juxtaposition of two to three dozens of cristae structures, which are known as an adaptation to the extreme nature of their flight with wing beats of hundreds per 
second $[84,125]$. By doubling the number of cristae, as compared to liver mitochondria in (A), hummingbirds' mitochondria decrease dramatically the volume of their matrix, providing a small volume sandwiched between the outer and the inner membrane (proton containment or roof above). We suggest that this morphological arrangement is crucial for localization and thus proton circulation along membrane surfaces, an adaptation to maximize ATP production.

Figure 6. Hyducton model unifies lipidomics and bioenergetics. (A) The purple membrane of haloarchaea. These integral membrane proteins can cover up to $50 \%$ of total membrane surface of haloarchaea and are associated with negatively charged sulfated glycolipids located in the outer leaflet (see text). (B) The proton circulation in E. coli according to: co-localization of respiratory complexes, represented by complex I, IV and ATP synthase $\left(\mathrm{B}_{1}\right)$; and aggregation of single components of the electron transport chain in microdomains $\left(\mathrm{B}_{2}\right)$. According to Erhardt et al. [50] and Llorente-Garcia et al. [51] high numbers of molecules per microdomain patch are observed (e.g. 70-180 and 40-60 molecules of cytochrome bd-I complex and ATP synthase), potentially creating powerful electrochemical poles. (C) The thylakoid membranes of cyanobacteria and plants. Delocalization of photosystem II and ATP synthase, respectively in grana and stroma membranes (cf. [149] and references therein). In active chloroplasts the luminal $\mathrm{pH}$ is around 5, whereas the stromal $\mathrm{pH}$ is around 8 [150]. This latter aspect might drive the asymmetrical distribution of polar lipids in thylakoid membranes, with an exclusive localization of diglycosidic headgroups on the lumenal side and the presence of monoglycosidic headgroups on both sides [52,152]. (D) Mitochondrial inner membrane and co-localization of complexes I, III and IV at flat regions of the mitochondria inner membrane cristae cf. Vogel et al. [154]. Ribbons of ATP synthase dimers localized in curved regions of the cristae $[155,156]$ might act as electrochemical poles for long distance proton transport in mitochondrial inner membranes. 
FIGURE 1

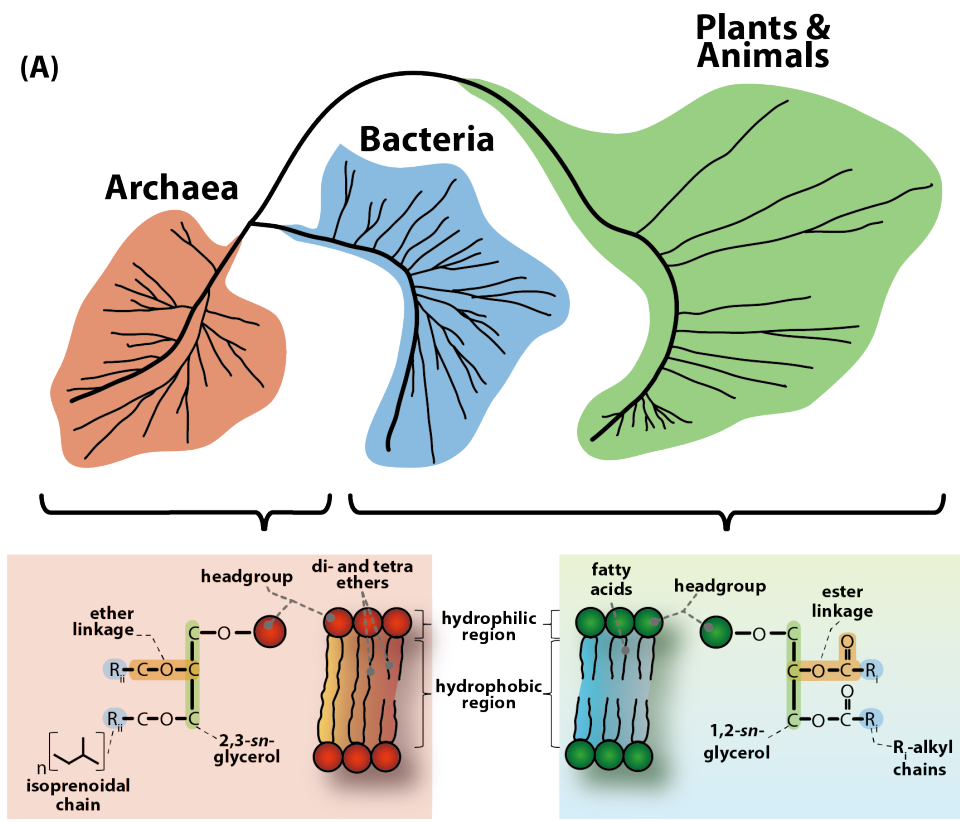

(B)

ANIONIC Zwitterionic $\quad$ Neutral
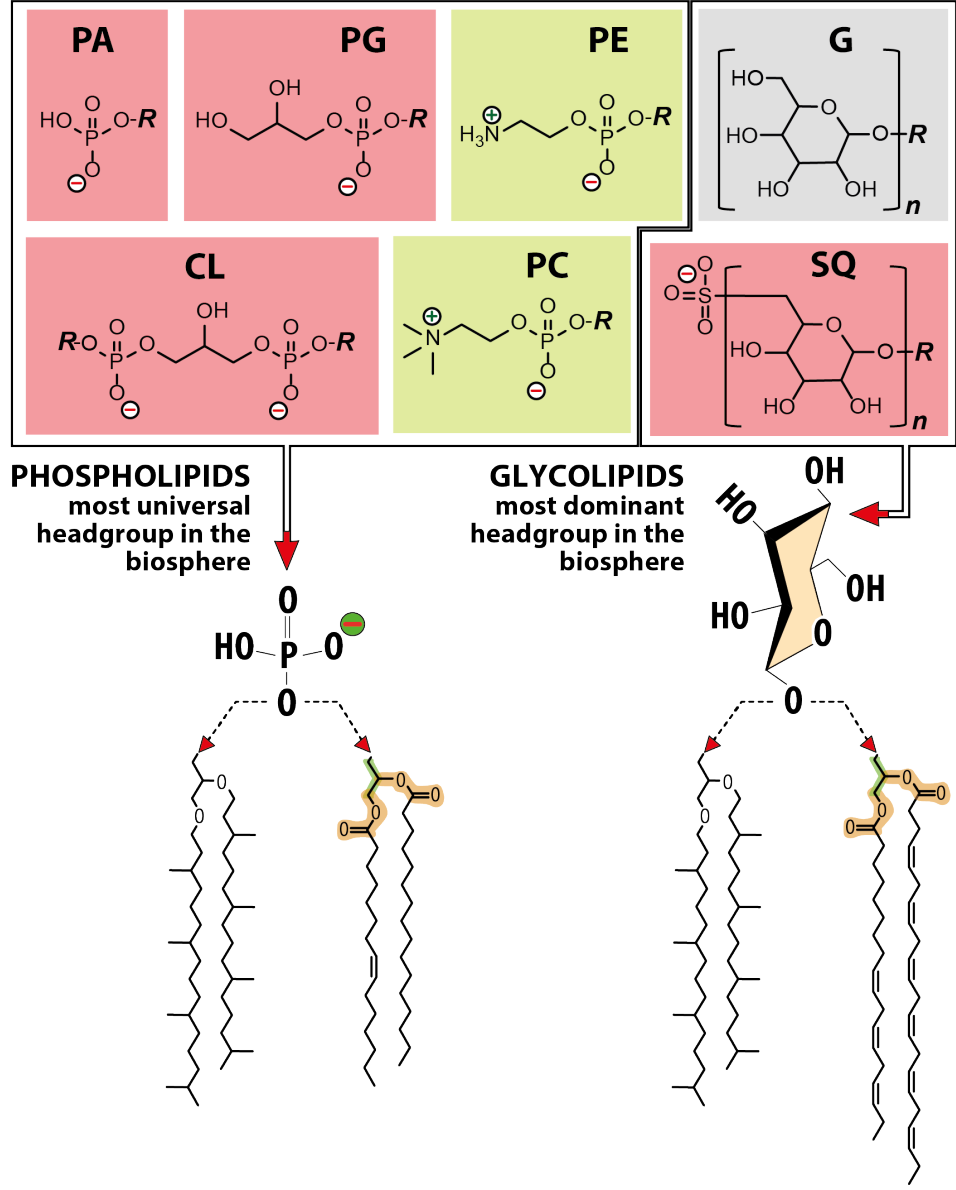
FIGURE 2

(A)

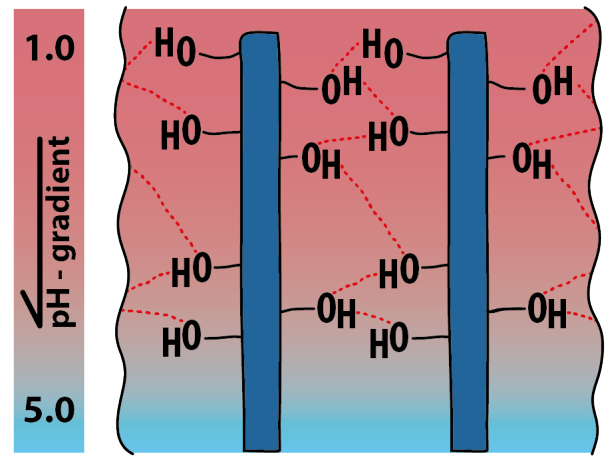

(B)

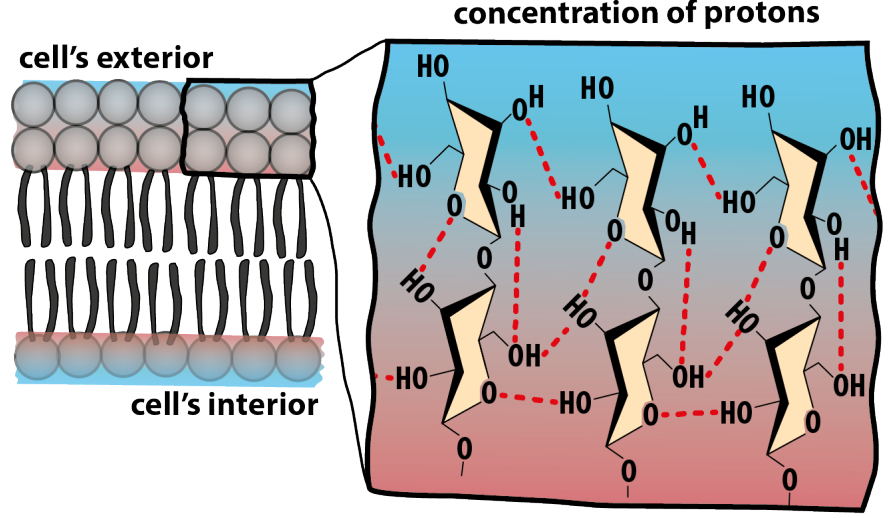


FIGURE 3
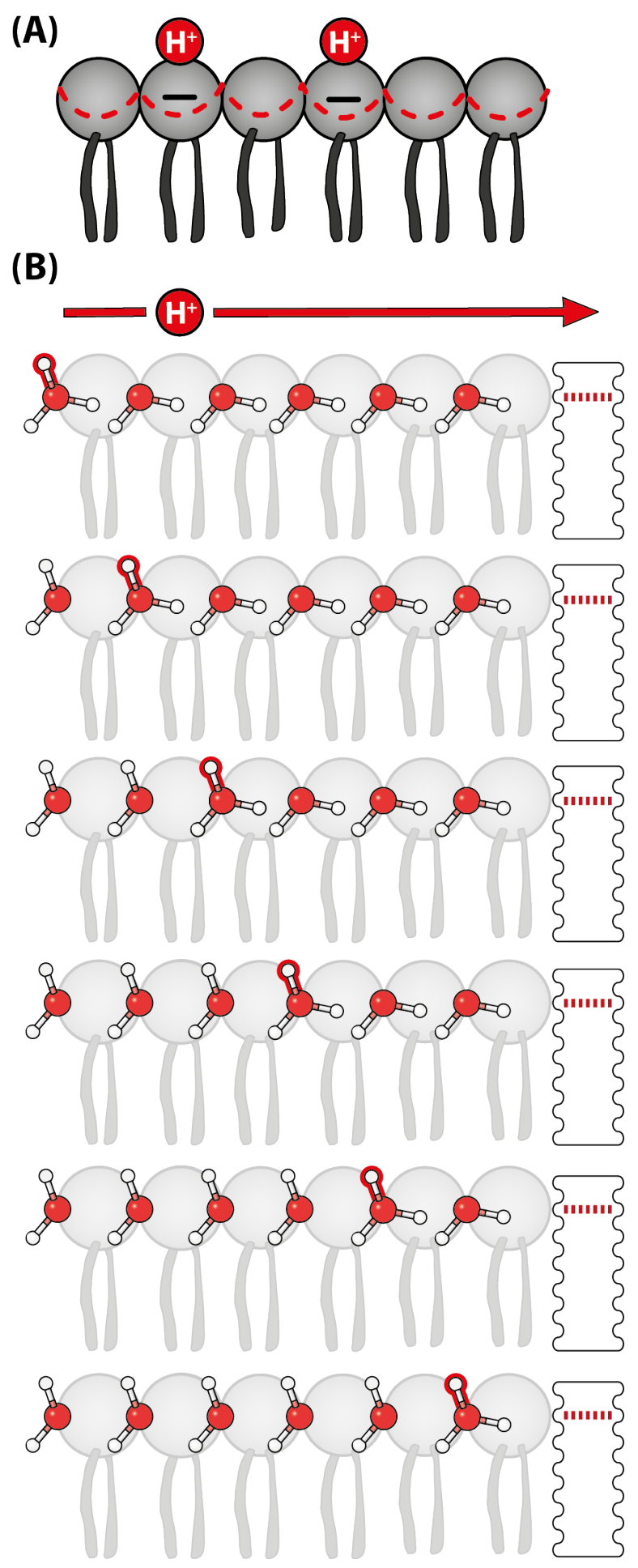
FIGURE 4

(A)

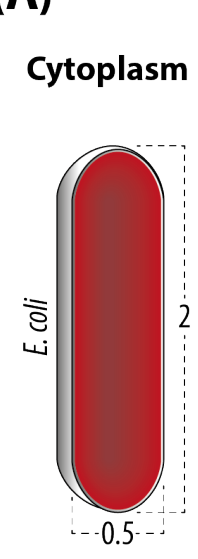

E. coli model

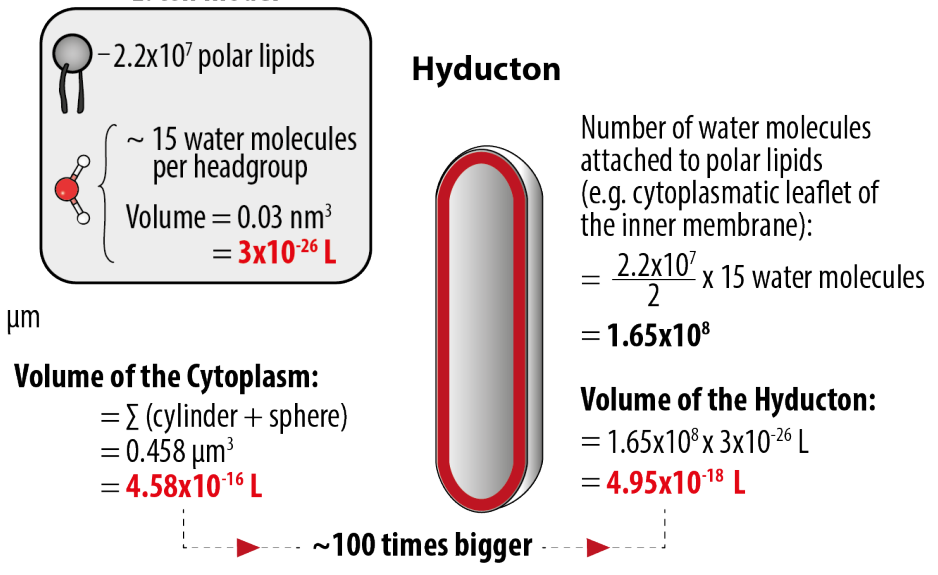

(B)

\begin{tabular}{c|cc}
$\mathbf{p H}$ & $\begin{array}{c}\mathrm{H}^{+} \text {in } \\
\text { cytoplasm }\end{array}$ & $\begin{array}{c}\mathrm{H}^{+} \text {in } \\
\text { hyducton }\end{array}$ \\
\hline $\mathbf{4}$ & 27581 & 298.0 \\
$\mathbf{5}$ & 2758 & 29.80 \\
$\mathbf{6}$ & 276 & 2.98 \\
\hline $\mathbf{7}$ & 27.6 & 0.298 \\
\hline $\mathbf{8}$ & 2.76 & 0.0298 \\
$\mathbf{9}$ & 0.276 & 0.00298 \\
$\mathbf{1 0}$ & 0.0276 & 0.000298
\end{tabular}


FIGURE 5

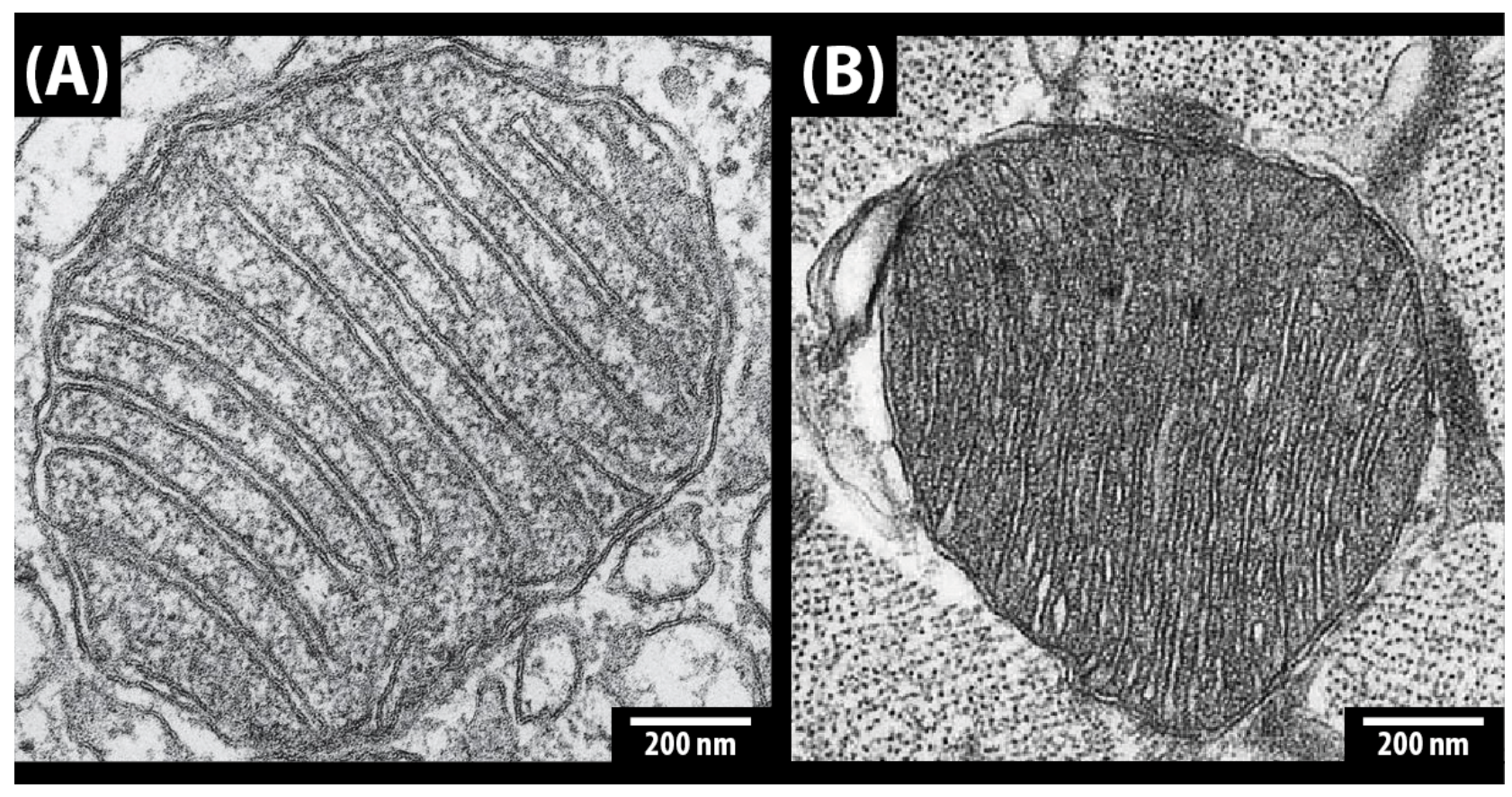


FIGURE 6

\section{(A) H. salinarum}

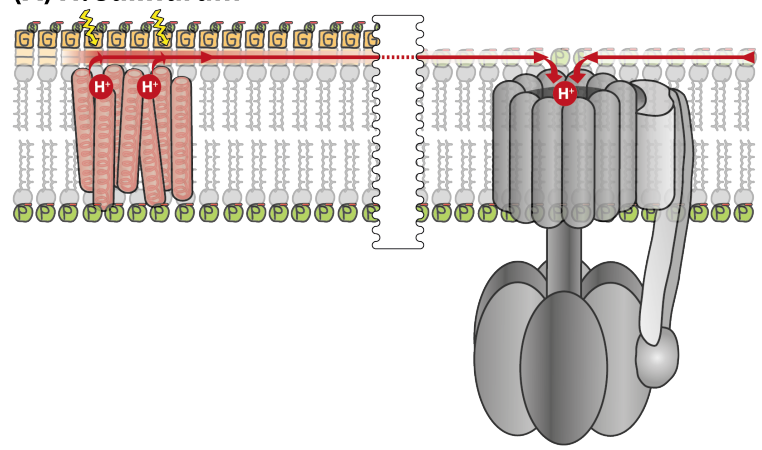

(B) E. coli (Supercomplexes)

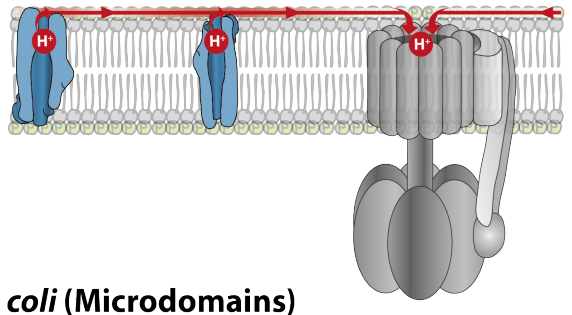

( $\left.\mathrm{B}_{2}\right)$ E. coli (Microdomains)

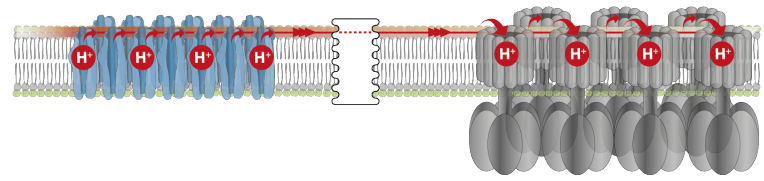

(C) Thylakoid membranes
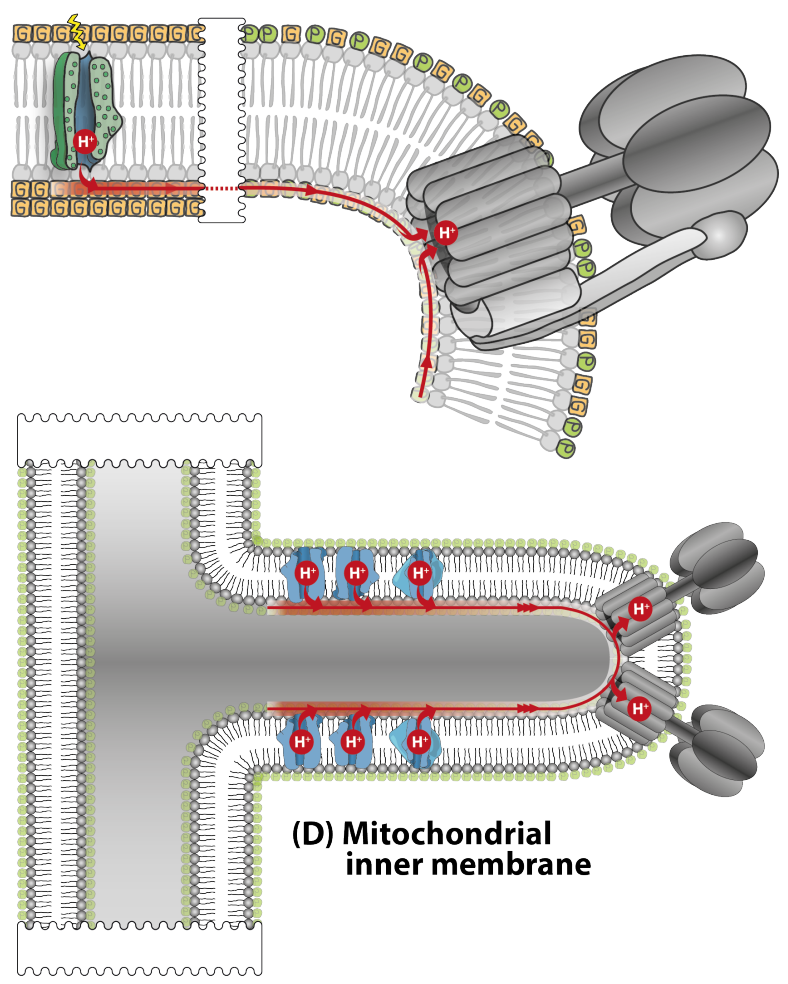
APPENDIX - TABLE A1

Table A1. Polar glycerolipid composition of selected acidophilic, neutrophilic and alkaliphilic microbial taxa. Archaea taxa are marked in gray shade. Temp=temperature; GlycoPhospho=glycosylphosphatidyl; Phospho=phosphatidyl; Glyco=glycosyl; Ref $=$ reference (see Main Text). Reported values of temperature and $\mathrm{pH}$ are according to growth conditions.

\begin{tabular}{|c|c|c|c|c|c|c|}
\hline Microbial taxa & pH & Temp & Glyco-Phospho & Glyco & Phospho & Ref. \\
\hline Thermoplasma acidophilum & 1.5 & 57 & + & + & + & 157 \\
\hline Acidiplasma aeolicum & 1.5 & 45 & + & + & + & 158 \\
\hline Methanococcus jannaschii & 6 & 85 & + & + & + & 159 \\
\hline Methanopyrus kandleri & 6.5 & 98 & + & + & + & 160 \\
\hline Pyrococcus furiosus & 7 & 96 & + & + & + & 160 \\
\hline Methanothermus fervidus & 6.5 & 78 & + & + & + & 160 \\
\hline Thermococcus kodakarensis & 6.5 & 85 & + & & + & 161 \\
\hline Sulfolobus acidocalcarius & 2.5 & 82.5 & & + & + & 160 \\
\hline Halobacterium salinarum & 7 & 30 & & + & + & 162 \\
\hline Halarchaeum salinum & 5.3 & 42 & & + & + & 163 \\
\hline Nitrosupumilus maritimus & 7.1 & 28 & & + & + & 31 \\
\hline Natromonas & 8.5 & 37 & & & + & 164 \\
\hline Methanosarcina acetivorans & 7 & 35 & & & + & 165 \\
\hline Thermus & 7.75 & 72.5 & + & + & + & 166,167 \\
\hline $\begin{array}{l}\text { Thermodesulfobacterium } \\
\text { commune }\end{array}$ & 7 & 70 & & + & + & 159 \\
\hline Thermoanaerobacter ethanolicus & 8 & 69 & + & & + & 168 \\
\hline Hydrogenothermus marinus & 6 & 65 & & + & + & 169 \\
\hline Aciditerrimonas ferrireducens & 3 & 50 & + & & + & 170 \\
\hline Acidiphilum & 3 & 20 & & & + & 171 \\
\hline Alkalimonas delamerensis & 10.25 & 37 & & & + & 172 \\
\hline Maritimibacter alkaliphilus & 10 & 30 & & & + & 173 \\
\hline Halomonas desiderata & 9.5 & 37 & & & + & 174 \\
\hline Methylobacter alcaliphilus & 9.25 & 30 & & & + & 175 \\
\hline Alcalilimnicola halodurans & 9 & 37 & & & + & 176 \\
\hline Halomonas campaniensis & 9 & 37 & & & + & 177 \\
\hline Dietzia natronolimnaios & 9 & 30 & & & + & 178 \\
\hline Alkalibacterium olivoapovliticus & 8.5 & 29.5 & & & + & 179 \\
\hline Escherichia coli & 7 & 37 & & & + & 33 \\
\hline Salmonella typhimurium & 7 & 37 & & & + & 33 \\
\hline Bacillus subtilis & 7 & 30 & & + & + & 34 \\
\hline Bacillus vulcani & 6 & 60 & + & & + & 180 \\
\hline Bacillus acidocalcarius & 3 & 60 & & + & + & 181 \\
\hline Bacillus acidicola & 4.5 & 30 & & + & + & 182 \\
\hline Bacillus alcalophilus & 10.5 & 30 & & & + & 34 \\
\hline
\end{tabular}




\begin{tabular}{lccccc} 
Bacillus firmus & 10.5 & 31 & & + & 34 \\
Leuconostoc fructosum & 6.5 & 30 & + & + & 183 \\
Leuconostoc ficulneum & 6.75 & 30 & + & + & 183 \\
Wenxinia marina & 7.75 & 36 & + & + & 184 \\
Woodsholea maritima & 7 & 28 & & + & 185 \\
Sulfurospirillum arcachonense & 7.2 & 26 & & + & 186 \\
Jannaschia helgolandensis & 7.5 & 27.5 & + & + & 187 \\
Pseudogracilibacillus & 7.5 & 29 & + & + & 188 \\
auburnensis & 8 & 59 & + & + & 189 \\
Chloroflexus aurantius & 7.5 & 34.5 & + & + & 190 \\
Anacystis nidulans & 6.8 & 32 & + & + & 191 \\
Rhodobacter sphaeroides & 9.25 & 30 & + & + & 189 \\
Spirulina strain "pantelleria" & 5.5 & 52.5 & + & + & 35 \\
Synechococcus sp. Y-7c-s & 7.5 & 21 & + & + & 193 \\
Prochlorococcus MED4 & 7.5 & 26 & & + \\
Gloeobacter violaceus & & & + & + \\
\hline
\end{tabular}

